\title{
Preconception paternal alcohol exposure exerts sex-specific effects on offspring growth and long-term metabolic programming
}

\author{
Richard C. Chang, Haiqing Wang, Yudhishtar Bedi and Michael C. Golding* (E)
}

\begin{abstract}
Background: Although clinical data support an association between paternal alcohol use and deficits in child neurocognitive development, the relationship between paternal drinking and alcohol-induced growth phenotypes remains challenging to define. Using an established mouse model of chronic exposure, previous work by our group has linked preconception paternal alcohol use to sex-specific patterns of fetal growth restriction and placental dysfunction. The aim of the present study was to investigate the long-term impact of chronic preconception paternal alcohol use on offspring growth and metabolic programming.

Results: Preconception paternal alcohol exposure induced a prolonged period of fetal gestation and an increased incidence of intrauterine growth restriction, which affected the male offspring to a greater extent than the females. While the female offspring of ethanol-exposed males were able to match the body weights of the controls within the first 2 weeks of postnatal life, male offspring continued to display an $11 \%$ reduction in weight at 5 weeks of age and a $6 \%$ reduction at 8 weeks of age. The observed growth deficits associated with insulin hypersensitivity in the male offspring, while in contrast, females displayed a modest lag in their glucose tolerance test. These metabolic defects were associated with an up-regulation of genes within the pro-fibrotic TGF- $\beta$ signaling pathway and increased levels of cellular hydroxyproline within the livers of the male offspring. We observed suppressed cytokine profiles within the liver and pancreas of both the male and female offspring, which correlated with the up-regulation of genes in the LiverX/RetinoidX/FarnesoidX receptor pathways. However, patterns of gene expression were highly variable between the offspring of alcohol-exposed sires. In the adult offspring of alcohol-exposed males, we did not observe any differences in the allelic expression of Igf2 or any other imprinted genes.
\end{abstract}

Conclusions: The impact of paternal alcohol use on child development is poorly explored and represents a significant gap in our understanding of the teratogenic effects of ethanol. Our studies implicate paternal exposure history as an additional and important modifier of alcohol-induced growth phenotypes and challenge the current maternalcentric exposure paradigm.

Keywords: Paternal alcohol use, Metabolic programming, Preconception exposure, Epigenetic programming, Developmental origins of adult disease, Growth restriction, Paternal exposure, Epigenetics, Fetal alcohol spectrum disorder

*Correspondence: mgolding@cvm.tamu.edu

Department of Veterinary Physiology and Pharmacology, College

of Veterinary Medicine and Biomedical Sciences, Texas A\&M University,

College Station, TX 77843-4466, USA 


\section{Background}

In clinical studies, fetal alcohol spectrum disorders (FASDs) associate with three broad developmental defects: distinctive craniofacial malformations, central nervous system defects and both prenatal and postnatal growth restriction $[1,2]$. The growth defects are characterized by reductions in height, weight, and body mass index that manifest at birth and continue to persist through young adulthood [3-5]. Indeed, although perceived as a childhood disorder, the growth phenotypes associated with FASDs are lifelong, with longterm growth restriction, as well as immune dysfunction, hyperinsulinemia, and other endocrine disruptions persisting into adulthood [5-10]. As a consequence of these persistent abnormalities, the life expectancy of patients with fetal alcohol syndrome is 34 years, which is $58 \%$ lower than the general population [11]. This dramatic reduction is very likely linked to the capacity of alcohol to significantly alter developmental programming, which promotes the early onset of adult disease $[12,13]$. However, while much research has focused on the neurological phenotypes of FASDs, the relationship between ethanol exposures and the long-term effects on growth and metabolic programming has received comparatively little attention.

FASD growth phenotypes can be linked to alcoholinduced intrauterine growth restriction mediated by impaired placentation [4, 14-17]. Impaired placentation, in turn, associates with poor cognitive development and long-term alterations in metabolic programming within the offspring [18-25]. Thus, the long-term effects of ethanol on growth and adult health may be linked to early developmental insults arising from a compromised fetalmaternal interface. Importantly, emerging research can now link a number of preconception exposures to compromised placentation and long-term alterations in metabolic function within the offspring [26-28]. These data further emphasize the importance parental histories of drug use, social stress, and environmental exposures have on child health and may help explain the enormous variation observed in FASD phenotypes and incidence [29].

The impacts parental histories of alcohol use have on child development are poorly explored and represent a significant gap in our understanding of the teratogenic potential of ethanol. This is especially true of preconception male alcohol exposures, which are a largely ignored aspect of patient history and are similarly underexplored in relevant biomedical models [30]. To this point, emerging epidemiological research indicates preconception paternal alcohol exposures have the ability to significantly influence child health and development [31, 32]. For example, clinical data can correlate paternal alcoholism with negative impacts on child behavior [33-38] and cognitive development [3943]. In addition, clinical associations between paternal drinking and increased rates of congenital abnormalities, as well as decreases in infant birth weight and head circumference, have been reported [44-46]. However, in these studies, additional and often uncontrolled factors such as nutrition, poor housing conditions, maternal stress, smoking, and parental alcohol use all exert independent effects on child growth and development. In this setting, it is virtually impossible to identify a direct link between preconception paternal alcohol use and child development $[47,48]$.

In rodent models, preconception paternal alcohol exposures associate with reductions in birth weight, increased incidences of congenital anomalies and cognitive impairment in the offspring [31, 49-58]. These observations join a growing body of work demonstrating the capacity of multiple stressors to alter the sperminherited developmental program [59-78] and suggest preconception paternal alcohol exposures may exert a long-term influence on offspring growth and development. In rodent models of maternal exposure, alcoholinduced abnormalities in the germline programming of the hypothalamic-pituitary stress response transmit through multiple generations via the male germline but are not maternally inherited [79]. Thus, alcohol has the ability to exert a lasting impact on the maleinherited developmental program, which, similar to studies employing models of intrauterine ethanol exposure [80-85], may exert long-term impacts on offspring health. However, no studies have yet directly examined the associations between paternal preconception alcohol exposures and long-term growth and metabolic programming within the offspring.

Recent work by our group has linked chronic preconception male alcohol exposure to fetal abnormalities in cholesterol trafficking, sex-specific patterns of growth restriction, disruptions in the regulation of imprinted genes and alterations in the genetic pathways regulating hepatic fibrosis [58]. The identification of altered cholesterol trafficking and increased markers of hepatic fibrosis within the fetus raise the prospect that these paternally inherited abnormalities have the capacity to significantly impact the long-term metabolic function of the offspring. This notion is further reinforced by the identification of compromised placental function in the offspring of alcohol-exposed males [58]. On the basis of these considerations, the aim of the present study was to investigate the long-term impact of chronic preconception paternal alcohol exposure on offspring growth and metabolic programming. 


\section{Materials and methods Animal work}

All experiments were conducted under AUP 20170308 and approved by the Texas A\&M University IACUC. In the outlined experiments, the male mice were of a C57BL/6(Cast7) background, while female mice were C57BL/6J (RRID:IMSR_JAX:000664). The C57BL/6(Cast7) strain of mice were generated in the Bartolomei laboratory and were selected to possess portions of a Mus musculus castaneus chromosome 7 and chromosome 12 (where at least 5 imprinting domains and more than 30 imprinted genes reside) bred onto a C57BL/6J background [86]. When using crosses between the B6(Cast7) strain and a C57BL/6J strain, we can distinguish the maternal and paternal alleles of select genes using $\mathrm{C} 57 \mathrm{BL} / 6$ (Cast7) and $\mathrm{C} 57 \mathrm{BL} / 6 \mathrm{~J}$ polymorphisms that we have identified previously $[58,87]$. The C57BL/6(Cast7) strain of mice is on a C57BL/6J background, which is susceptible to alcohol-induced teratogenesis $[88,89]$.

To investigate the long-term impact of alcohol exposure on the male-inherited developmental program, an established and well-characterized mouse model of chronic alcohol exposure was employed [90]. Here, postnatal day 90, adult males were provided limited access to ethanol during a 4-h window of the night cycle. This rodent model (Drinking in the Dark) promotes the voluntary consumption of ethanol in sufficient quantities to achieve pharmacologically meaningful blood alcohol concentrations, typically in excess of $150 \mathrm{mg} / \mathrm{dL}$ [58, 91]. In a study examining the drinking patterns of 10,424 college freshmen in the USA, one in five males reported routinely consuming $10+$ drinks in a single session, while half reported drinking beyond the binge level $(5+$ drinks in a single session) $[92,93]$. Thus, the blood alcohol levels observed in our model reflect a range frequently obtained by college age males [92-94].

Here, individually caged, postnatal day 90, adult males were fed a standard diet (catalog\# 2019, Teklad Diets, Madison, WI, USA) and maintained on a 12-h light/dark cycle. Males were provided limited access to ethanol during a 4-h window, beginning $1 \mathrm{~h}$ after the initiation of the dark cycle [58]. During this 4-h window, experimental males were provided access to a solution of $10 \%(\mathrm{w} / \mathrm{v})$ ethanol (catalog\# E7023; Millipore-Sigma, St. Louis, MO, USA) and $0.066 \%(\mathrm{w} / \mathrm{v})$ Sweet'N Low (Cumberland Packing Corp, Brooklyn NY, USA), while control males received a solution of $0.066 \%(\mathrm{w} / \mathrm{v})$ Sweet'N Low alone. After each session, the amount of fluid consumed by each mouse was recorded.

The addition of Sweet'N Low is necessary to encourage male mice to develop consistent drinking habits. Although, prolonged exposure to a $10 \%$ Sweet'N Low solution has previously been shown to drive the development of glucose intolerance through functional alterations to the intestinal microbiota, the concentrations employed in our studies were 150-fold lower than those utilized in these previous experiments [95]. In addition, we were careful to ensure that mice in both preconception treatment groups consumed equivalent fluid volumes and therefore received identical exposures to Sweet'N Low.

Once consistent patterns of drinking were established, males were maintained on this protocol for a period of 70 days, which corresponds to the length of approximately two complete spermatogenic cycles, thereby ensuring that both pre-meiotic and post-meiotic spermatids were exposed to alcohol $[96,97]$. Once the 70-day preconception treatment was achieved, two naturally cycling females were placed into a new cage along with each exposed male. During these matings, males were not provided access to the alcohol/control preconception treatments. The next morning, matings were confirmed by the presence of a vaginal plug and both the male and female mice were returned to their original cages. Males were allowed a 24-h rest period, during which the preconception exposure was resumed and then used in a subsequent mating. This procedure was repeated until each male had produced a minimum of three litters.

Pregnant dams were maintained on a breeder diet (catalog\# 5058; LabDiet, St. Louis, MO, USA), subjected to minimal handling and monitored for delivery twice daily. One week after birth, fifteen male and female offspring from each preconception treatment group were randomly selected from across at least five different litters and monitored for postnatal growth and development. Mice were maintained on a standard diet (catalog\# 2019; Teklad Diets, Madison, WI, USA) and body weight was recorded weekly, for 8 weeks. Between seven and 8 weeks of age, metabolic function was assayed using glucose and insulin tolerance tests. After 8 weeks of age, offspring were terminated and both physiological fluids and tissues were collected.

\section{Insulin and glucose tolerance tests}

Beginning at 7 weeks of age, mice were fasted overnight for $12 \mathrm{~h}$ and tested for glucose and insulin tolerance, with a minimum of a 1-week recovery time between these separate tests. Here, mice received a single intraperitoneal injection of D-glucose ( $2 \mathrm{~g} / \mathrm{kg}$ body weight; catalog\# SG8270; Millipore-Sigma, St. Louis, MO, USA) or insulin (1 unit/kg body weight; catalog\# 89508-914; VWR, Radnor, PA, USA) and blood glucose levels measured using Clarity Plus-Blood Glucose Test Strips (catalog\# DTG-GL5PLUS; Clarity Diagnostics, Boca Raton, Florida USA) from $5 \mu \mathrm{L}$ of blood drawn from the tail vein. For 
glucose tolerance tests, blood glucose levels were measured before the injection of glucose and at 30, 60, 90 and 120 min post-injection. For insulin tolerance tests, blood glucose levels were measured before the injection of insulin and at 15, 30, 45 and $60 \mathrm{~min}$ after insulin injection. Each experimental group contains fifteen male and female animals $(n=15)$.

\section{Liver perfusion assay}

One week after the final evaluation of metabolic parameters, six males and six females from each group were randomly selected to evaluate insulin signaling and levels of AKT phosphorylation (Ser473) in the liver. Mice were fasted $12 \mathrm{~h}$ overnight and anesthetized with $2 \%$ isoflurane [98], until animals achieved a deep plane of anesthesia, demonstrating a lack of a righting reflex and a 50\% reduction in respiratory rate. At this point, the body cavity of the mouse was opened and the liver perfused with either $37{ }^{\circ} \mathrm{C}$ PBS $+0.1 \%$ BSA (Control) or 2 units $/ \mathrm{kg}$ of an insulin solution (10 nM insulin, Sigma, in PBS + 0.1\% BSA; catalog\# 89508-914; VWR, Radnor, PA, USA) at a flow rate of $100 \mathrm{ml} / \mathrm{h}$. Here, the suprahepatic vessel was clamped and a 27-gauge syringe inserted into the intrahepatic cava. After observing liver perfusion, the hepatic portal vein was cut open. During this procedure, a nose cone containing gauze soaked in isoflurane was kept over the nose of the animal and removed only when the rate of respiration dipped down below $25 \%$. After 5 min, animals were euthanized by cervical dislocation and tissues of interest, including liver, kidney and pancreas collected and snap-frozen in liquid nitrogen. Each experimental group contains six different animals $(n=6)$.

\section{Western immunoblot analysis}

Liver tissue samples were collected and homogenized in a Tris lysis buffer including $50 \mathrm{mM}$ Tris, $1 \mathrm{mM}$ EGTA, $150 \mathrm{mM} \mathrm{NaCl}, 1 \%$ Triton X-100, $1 \% \beta$-mercaptoethanol, $50 \mathrm{mM} \mathrm{NaF}, 1 \mathrm{mM} \mathrm{Na} 3 \mathrm{VO} 4$ and $\mathrm{pH}$ 7.5. Samples were separated on $10 \%$ sodium dodecyl sulfate-polyacrylamide gels by electrophoresis and transferred to nitrocellulose membranes. The primary antibodies used in this study were as follows: anti-phosphorylated protein kinase $B(A K T)$ at Serine 473 (catalog\#700392; RRID:AB_2532320; Thermo-Fisher, Waltham, MA, USA) and anti- $A K T$ used for loading control (catalog\#44609G; RRID:AB_2533692; Thermo-Fisher, Waltham, MA, USA). Blots were visualized by using secondary antibodies conjugated to horseradish peroxidase (catalog\# sc-2004; RRID:AB_631746; Santa Cruz Biotechnology, Santa Cruz, CA, USA) and an enhanced chemiluminescence detection system (Pierce, Rockford, IL, USA). Relative $A K T$ phosphorylation was derived as a ratio to total $A K T$. Band intensities were quantified by densitometry using ImageJ (RRID:SCR_003070; National Institutes of Health, Bethesda, MD, USA). Each experimental group contains six different animals $(n=6)$.

\section{Measurement of physiological parameters}

Male plasma alcohol concentrations were measured using an Ethanol Assay Kit (catalog\# ECET100; BioAssay Systems, Hayward, CA, USA) according to manufacturer's protocol. Animals were euthanized by cervical dislocation, blood collected postmortem and plasma insulin levels determined using the Mouse Insulin ELISA kit (catalog\# EMINS; Thermo-Fisher, Waltham, MA, USA), according to the recommended protocol. Levels of $I L 1 B$, IL6, INFg and TNFa were determined using commercial ELISA assays (catalog\# KMC0061 and KMC0011; Thermo-Fisher, Waltham, MA, USA and catalog\# Ab100689 and Ab100747; Abcam, Cambridge, MA, USA). Total cholesterol levels were determined using the Total Cholesterol Assay Kit (catalog\# STA-384; Cell Biolab, Inc, San Diego, CA USA), according to the recommended protocol. The comparative levels of lowdensity and high-density lipoproteins were determined using a Cholesterol Assay Kit (catalog\# ab65390; Abcam, Cambridge, MA, USA), according to the recommended protocol. The levels of hydroxyproline were determined using the Hydroxyproline Assay Kit (catalog\# MAK008; Millipore-Sigma, St. Louis, MO, USA), following to the recommended protocol.

\section{RNA analyses}

Total RNA was isolated from 8-week-old offspring liver using the RNeasy Plus Mini Kit, (catalog\# 74134; Qiagen, Germantown MD, USA) according to manufacturer's instructions. Samples were randomized prior to RNAseq library preparation. Libraries were generated from 10 ng of RNA using the TruSeq RNA Sample Preparation kit (Illumina, San Diego, CA, USA) and pooled for sequencing on an Illumina HiSeq 2500 at the Whitehead Genome Technology Core (Cambridge, MA, USA). Sequencing data were demultiplexed and aligned using STAR (RRID:SCR_015899) with default parameters [99].

\section{RNA deep sequencing data analysis, selection of candidate mRNAs and functional enrichment}

Following deep sequencing, Bowtie (RRID:SCR_005476) and Tophat (RRID:SCR_013035) were used to align 50-bp-length, paired-end reads into transcripts using the Mus musculus (UCSC version mm10) reference genome. To measure the relative abundance of each transcript, the resulting aligned reads were analyzed using the Cufflinks suite (RRID:SCR_014597). Expression was quantified as the number of reads mapping to a gene divided by the gene length in kilobases and the total number of mapped 
reads in millions and designated as fragments per kilobase of exon per million fragments mapped (FPKM). To select differentially expressed transcripts, a volcano plot measuring statistical significance and magnitude of fold change was generated based on the log2 fold change (Y-axis) and $-\log 10 p$ value from Cuffdiff analysis within the Cufflinks suite (RRID:SCR_014597) (X-axis). Differentially expressed mRNAs were selected on the basis of linear p-value cutoff of 0.05 , which was considered significant and highlighted by colored dots in the volcano plot. Subsequently, functional clusters were identified by applying Ingenuity Pathway Analysis (RRID:SCR_008653; Ingenuity System Inc, Redwood City, CA, USA) [100].

\section{Real-time RT-qPCR analysis of gene expression}

Total RNA was isolated from 8-week liver using the RNeasy Plus Mini Kit, (catalog\# 74134; Qiagen, Germantown, MD, USA) according to manufacturer's instructions. One microgram of purified total RNA was treated with amplification grade DNase I (catalog\# AMPD1; Millipore-Sigma, St. Louis, MO, USA) according to the manufacturer's recommendations and seeded into a reverse transcription reaction using the High Capacity cDNA Reverse Transcription Kit (catalog\# 4368814; ThermoFisher, Waltham, MA, USA), where the reaction mixture was brought to $25^{\circ} \mathrm{C}$ for $10 \mathrm{~min}, 37^{\circ} \mathrm{C}$ for $120 \mathrm{~min}$ and then $70^{\circ} \mathrm{C}$ for $5 \mathrm{~min}$. Relative levels of candidate gene transcripts were analyzed using the Dynamo Flash mastermix (catalog\# F-415XL; Thermo-Fisher, Waltham, MA, USA) according to the recommended protocol. Reactions were performed on a Bio-Rad CFX384. Primer sequences are listed in Additional file 1.

\section{Data handling and statistical analysis}

For all experiments, measures were input into the statistical analysis program GraphPad (RRID:SCR_002798; GraphPad Software, Inc., La Jolla, CA, USA), and statistical significance was set at alpha $=0.05$. All datasets were first verified for normality using the Brown-Forsythe test. In this study, the effect of two independent variables (sex vs. preconception treatment) was assessed using an analysis of variance test (ANOVA), and differences among the means evaluated using Sidak's post hoc test of contrast. No interactions $(p>0.05)$ were observed between fetal weight and sire weight, fetal weight and dam weight, or litter size and fetal weight. Pups were defined as intrauterine growth restricted (IUGR) if their weight at 1 week of age was less than the average weight of the control group less two standard deviations [101]. The IUGR ratio was calculated by dividing the number of IUGR offspring by the total number of fetuses in each litter. To determine the significance of IUGR ratio between groups, the IUGR ratio was first transformed by arcsine square root prior to unpaired $t$ test examination. The offspring were weighed weekly from week 1 through week 8 . The average growth rate was calculated using the following equation: [(bodyweight at week 8 -bodyweight at week 1 )/bodyweight at week 8].

For analysis of gene expression, the replicate cycle threshold $(\mathrm{Ct})$ values for each transcript were compiled and normalized to the geometric mean of three validated reference genes. Transcripts encoding tyrosine 3-monooxygenase/tryptophan 5-monooxygenase activation protein zeta (Ywhaz-NM_011740), mitochondrial ribosomal protein L1 (Mrpl1-NM_053158) and hypoxanthine-phosphoribosyl transferase (Hprt-NM_013556) were measured as reference genes. Each of these reference genes were validated for stability across treatment groups using methods described previously [102]. Normalized expression levels were calculated using the $\mathrm{ddCt}$ method described previously [103]. Relative fold change values from each biological replicate were determined and transferred into the statistical analysis program GraphPad. For comparisons including sex and preconception treatments, an analysis of variance (ANOVA) was utilized and Sidak's analysis applied to comparisons with $p$ values $<0.05$. For single comparisons, an unpaired student's $t$ test was applied. In all instances, we have marked statistically significant differences with an asterisk.

In our mouse model, distinct single nucleotide polymorphisms between the maternal (C57BL/6J) and paternal (C57BL/6(Cast7) strains [86] allowed us to track allelic patterns of gene transcription for multiple imprinted genes. For RNA sequence-based comparisons of allelic patterns of imprinted gene expression, the proportion of single nucleotide polymorphisms was measured using the Integrative Genome Viewer (RRID:SCR_011793) software package and analyzed using either Chi-squared analysis or, if read counts were less than 5, a Fisher's Exact test.

\section{Results}

Chronic paternal ethanol exposure associates with delayed parturition and intrauterine growth restriction

\section{of the offspring}

In clinical studies, FASDs are characterized by reductions in height, weight and body mass index that manifest at birth and persist through young adulthood $[3,5]$. However, no studies have determined the capacity of chronic preconception male alcohol exposures to contribute to these phenotypes or impact postnatal growth. To address this gap, adult male mice were exposed to ethanol every day for a 70-day period, using a previously described limited access model [90]. Similar to our previous studies [58], no differences in fluid consumption were observed between the ethanol and control preconception 
treatment groups (Fig. 1a). Ethanol exposures were measured on day 10 and again on day 70 of the preconception treatment course, and in the ethanol-exposed males, it yielded average plasma alcohol levels of 178 and $245 \mathrm{mg} /$ $\mathrm{dL}$, respectively (Fig. 1b). During the course of the 70-day preconception treatments, no differences in weight gain could be detected between ethanol-exposed or control males (Fig. 1c). After 70-days of preconception treatment, exposed males were mated to six- to eight-week-old females. At no point during these experiments were the females ever exposed to the preconception treatments.

Litters from each of the preconception control and ethanol-exposed treatment groups were termed and the length of gestation recorded. Unexpectedly, preconception alcohol exposure associated with a $10 \%$ increase in the length of gestation $(p<0.05)$, with litters sired by ethanol-exposed males born on day 23 versus day 21 for the control litters (Fig. 1d). No differences in litter size were observed between the preconception treatment groups (Fig. 1e). At 1 week of age, paternal alcohol exposure associated with a $25 \%$ reduction in the body weight of male offspring and a $15 \%$ reduction in the body weights of the female offspring (Fig. 1f, g, $p=0.004, p=0.017$ ). Accordingly, the ratio of offspring displaying intrauterine growth restriction [101] was significantly increased in the offspring of ethanol-exposed males (Fig. $1 \mathrm{~h}, p=0.04$ ). To determine the long-term impact of the observed growth restriction, fifteen male and fifteen female offspring were randomly selected from across five different litters and their weights tracked for 8 weeks. Interestingly, while the female offspring of ethanol-exposed males were able to match the body weights of the controls within the first 2 weeks of life, male offspring sired by alcoholexposed fathers continued to display an $11 \%$ reduction in weight at 5 weeks of age $(p=0.005)$ and a $6 \%$ reduction at 8 weeks of age $(p=0.0003$, Fig. 1f, g). To determine whether this difference was associated with altered growth parameters, the average growth rates for each group were calculated. Similar to clinical studies of IUGR [104], both the male and female offspring of alcoholexposed males displayed accelerated postnatal weight gain compared to the controls (Fig. 1i). However, as in clinical reports of FASD children [5], the male offspring of ethanol-exposed fathers remained smaller than the

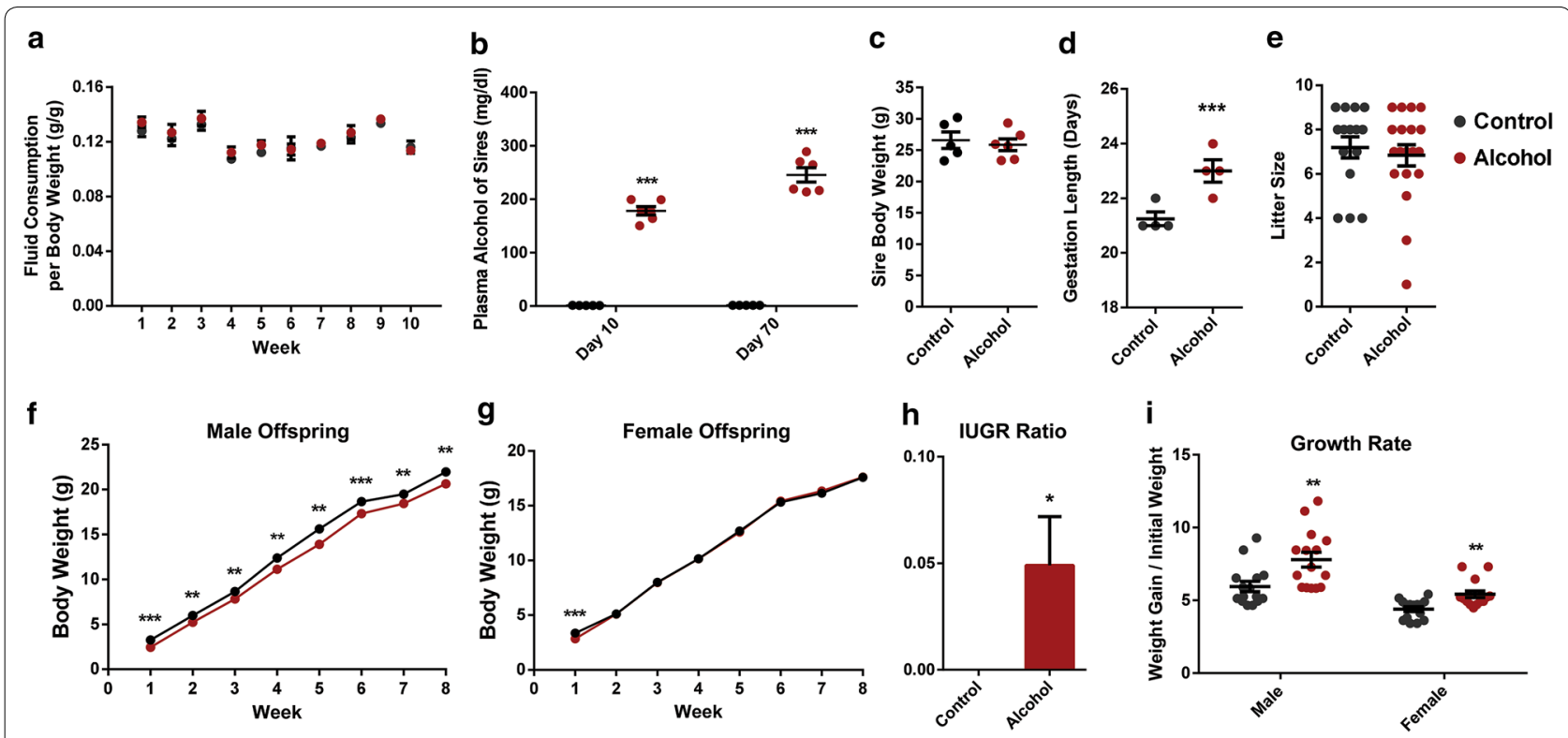

Fig. 1 Preconception paternal ethanol exposure associates with intrauterine growth restriction (IUGR) and altered postnatal growth. a Average fluid consumption normalized by body weight during the preconception treatment period ( $n=5$ control and 6 experimental males). b Plasma alcohol concentrations measured at Day 10 and Day 70 of the 70-day preconception exposure period ( $n=5$ control and 6 alcohol-exposed males). Blood alcohol levels were measured $2 \mathrm{~h}$ into the 4 -h exposure period. $\mathrm{c}$ Average body weight of sires at the end of the 70-day preconception exposure period ( $n=$ five control and six experimental males). $\mathbf{d}$ Average length of gestation for litters sired by alcohol-exposed and control males $(n=4)$. $\mathbf{e}$ Average litter size between the preconception ethanol and control treatment groups ( $n=15$ control 19 alcohol). Postnatal weights of $\mathbf{f}$ male and $\mathbf{g}$ female offspring sired by ethanol-exposed and control males measured over 8 weeks ( $n=15$ males, 15 females from each treatment group). $\mathbf{h}$ Average rate of IUGR at 1 week of age. The graph depicts the number of IUGR pups/the total number of offspring counted in each group. $\mathbf{i}$ Rate of bodyweight gain over 8 weeks of postnatal life. Error bars represent SEM ${ }^{*} p<0.05,{ }^{* *} p<0.01$ and ${ }^{* * *} p<0.001$ [comparisons between $10 \%$ (w/v) ethanol plus $0.066 \%$ (w/v) Sweet'N Low (alcohol) vs. 0.066\% (w/v) Sweet'N Low alone (control) preconception treatments]. Data were analyzed using either an unpaired $t$ test, arcsine transformed and an unpaired $t$ test with Welch's correction applied or used in a two-way ANOVA followed by Sidak post hoc analysis 
offspring of the controls. For clarity, Additional file 2 contains the data from Fig. 1 presented in table form, with the number of replicates, statistical significance and formula used to derive each measure presented. No significant interactions between litter size and growth rate were detected using ANOVA.

\section{Chronic paternal ethanol exposure associates with long-term effects on glucose metabolism and insulin signaling}

In clinical studies, IUGR children develop impaired insulin responses to glucose and similar observations have been reported in both sheep and rat models of fetal growth restriction [105-108]. To determine whether the IUGR observed in the offspring of ethanol-exposed males impacted the long-term regulation of blood sugar homeostasis, glucose and insulin stress tests were conducted. Paternal ethanol consumption associated with a significant decrease in both fasting blood glucose and insulin levels in male offspring, while female offspring displayed an increase in fasting glucose levels only (Fig. 2a, b). At 8 weeks of age, these alterations were associated with exaggerated insulin responses in both glucose and insulin tolerance tests within the male offspring, while females displayed a modest impairment in their glucose tolerance test (Fig. 2c-f). To identify the pathophysiological basis of these altered parameters, mice were killed at 8 weeks of age, their organs weighed and tissues collected for molecular analysis. The male offspring of ethanol-exposed sires displayed a $13 \%$ reduction in visceral fat $(p=0.04)$, and while pancreas weight tended to be smaller $(p=0.1)$; this did not reach statistical significance (Fig. 2g). No differences in organ weights were noted in the female offspring (Fig. 2h).

To determine whether preconception alcohol exposure impacted the insulin signaling pathway, six randomly selected, eight-week-old male and female mice from each preconception treatment group had their livers perfused with insulin to assay $A k t$ signaling. $A K T$ phosphorylation (Ser473) in the insulin-perfused livers was increased
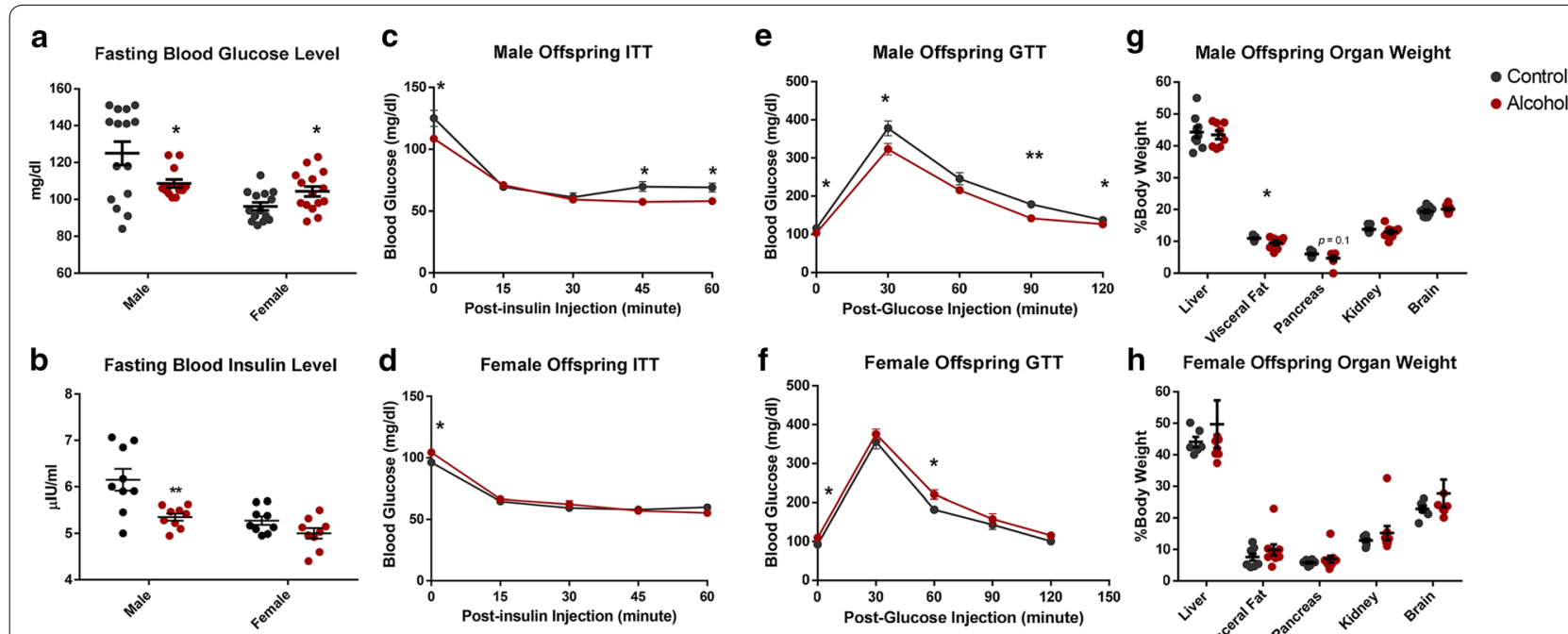

Alcohol

i
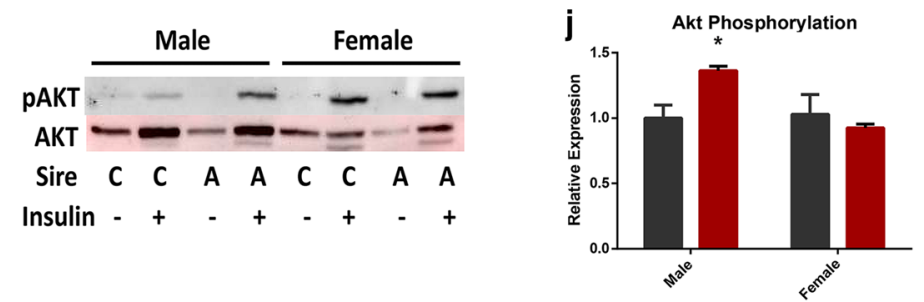

Fig. 2 Chronic preconception male ethanol exposure exerts sex-specific effects on offspring metabolic function. a Fasting blood glucose levels compared between preconception treatments ( $n=15$ males, 15 females). $\mathbf{b}$ Fasting insulin levels compared between preconception treatments ( $n=$ nine males, nine females). c-f Glucose tolerance (GTT) and insulin tolerance (ITT) tests in the offspring of ethanol-exposed and control males ( $n=15$ males, 15 females). Organ weights of $\mathbf{g}$ male and $\mathbf{h}$ female offspring compared between the two preconception treatment groups $(n=$ nine males, nine females). i Representative immunoblot comparing total and phosphorylated AKT (Ser473) between male and female offspring sired by ethanol-exposed and control males ( $n=$ six males and six females). j Densitometry analysis of immunoblots comparing total and phosphorylated $\operatorname{AKT}(n=$ six males and six females). Data analyzed using either an unpaired $t$ test or a two-way ANOVA followed by Sidak post hoc analysis. Error bars represent SEM ${ }^{*} p<0.05$ and ${ }^{* *} p<0.01$ (comparisons between alcohol and control preconception treatments) 
by $26 \%$ in the male offspring of ethanol-exposed sires $(p=0.014)$, while female offspring were identical to the controls (Fig. 2i, j). Collectively, these observations indicate preconception male alcohol exposure is associated with programmed metabolic dysfunction, and is similar to data reported in long-term clinical studies of FASD children, in which disruptions in the endocrine regulation of blood glucose levels have been observed [6].

\section{Preconception paternal alcohol exposure associates with markers of hepatic fibrosis in the adult offspring} In previous studies, intrauterine growth restriction has been associated with alterations in offspring blood lipid profiles and the development of adolescent non-alcoholic fatty liver disease (NAFLD) [19, 109]. In our previous studies examining the fetal development of offspring sired by ethanol-exposed males, we observed alterations in placental cholesterol transport and the emergence of molecular markers associated with hepatic fibrosis [58]. To determine whether the legacy of preconception ethanol exposure previously identified in the fetal liver extends into postnatal life, the expression of the genes identified in the transcriptomic analysis of the fetal liver were examined by RT-qPCR [58]. In male offspring, and to a lesser extent females, preconception paternal ethanol exposure continued to associate with persistent alterations in the expression of multiple collagen subtypes and core components of the TGF- $\beta$ signaling pathway driving hepatic fibrosis [110], even at 8 weeks of age (Fig. 3a-d). To determine if this transcriptional signature associated with increased molecular markers of hepatic fibrosis, we measured total levels of hydroxyproline, a commonly employed biomarker of this condition [111]. Given the trend toward a reduction in weight (Fig. 2g), we also assayed this marker in the pancreas. The male offspring of ethanol-exposed sires displayed a $13 \%$ increase in hydroxyproline levels within the liver $(p<0.01)$, while levels of hepatic hydroxyproline in the female offspring were identical to the controls (Fig. 3e). No differences in levels of hydroxyproline content could be detected in the pancreas in either males or females (Fig. 3f). These results indicate that the molecular signature previously identified in the fetal liver [58] persists into postnatal life and suggests the existence of a heightened fibrotic response within the livers of male offspring sired by alcoholexposed fathers.

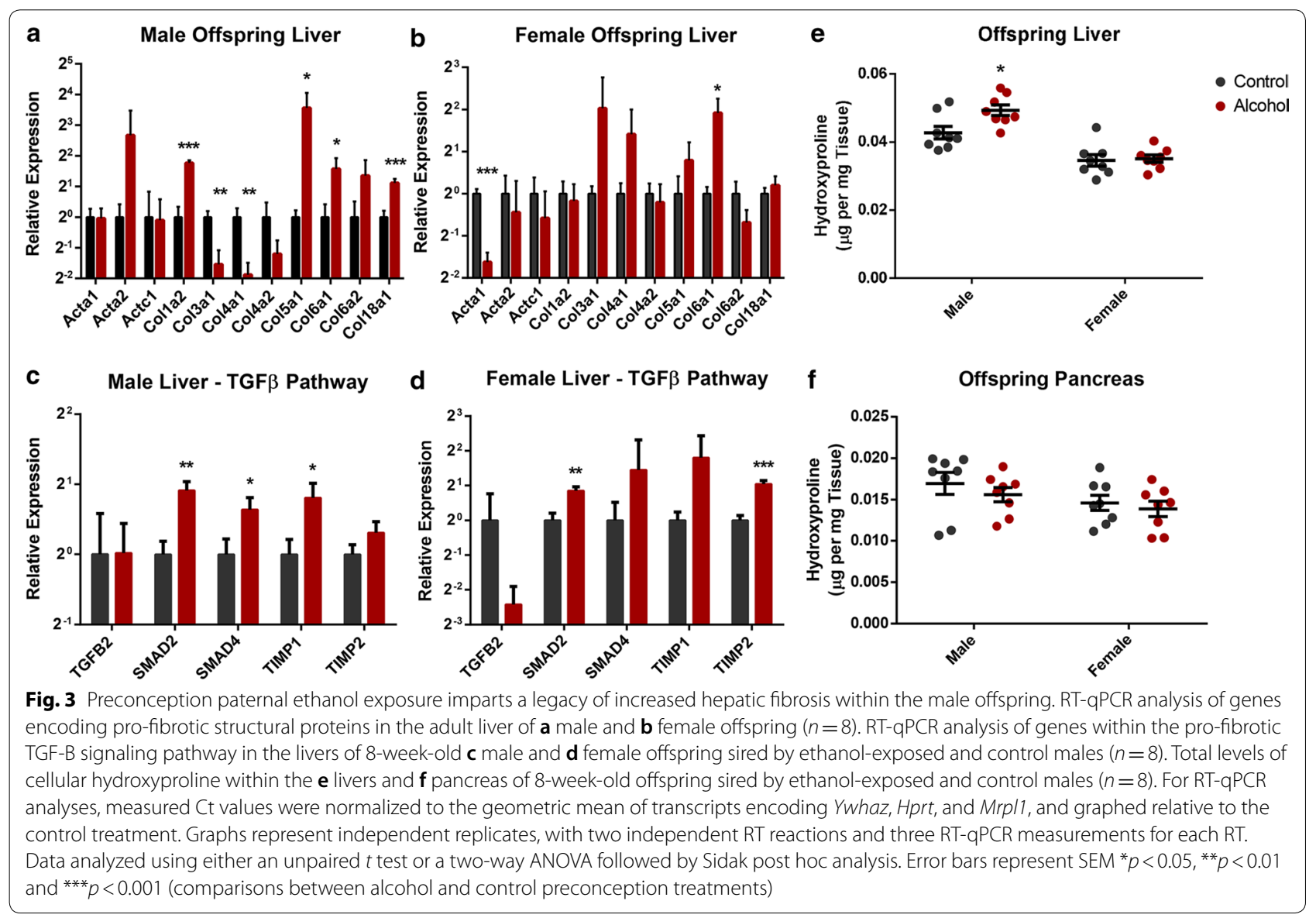




\section{Preconception paternal alcohol exposure associates with disruptions in hepatic gene expression within the adult offspring}

Given the persistent changes in gene expression identified between the fetal [58] and adult liver (Fig. 3), we next assayed genome-wide patterns of transcription in the adult liver of male offspring using deep sequencing. These analyses identified 548 differentially expressed genes, with 351 down-regulated and 197 up-regulated transcripts identified ( $q=0.05$; Fig. 4a). In these analyses, we observed a high level of variability, where not all of the differentially expressed genes were consistent between the between the offspring of alcohol-exposed sires (Fig. 4b). Using Ingenuity Pathway Analysis, we identified up-regulation of candidate genes participating in the genetic pathways regulating both $L X R / R X R$ and $F X R / R X R$ activation, as well as down-regulation of genes participating in the cholesterol super-pathway of biosynthesis (Fig. 4c). Although we were able to validate multiple candidate genes participating in $L X R / R X R$ and $F X R / R X R$ signaling pathways, identified candidate genes participating in pathways regulating cholesterol biosynthesis were not significantly different (Fig. 4d). However, we did observe a $15 \%$ increase in the levels of total cholesterol in the livers of the male offspring of alcoholexposed sires $(p=0.04$, Fig. 4e). These differences were not linked to specific increases in either high-density or low-density lipoproteins, and no differences in their proportional relationship could be detected (Fig. 4f-h). In contrast to males, female offspring of alcohol-exposed sires displayed a $23 \%$ reduction in the proportion of highdensity lipoproteins to total cholesterol, as compared to the female offspring of control fathers ( $p=0.03$, Fig. $4 \mathrm{~h})$. No differences in total cholesterol, high-density and lowdensity lipoproteins or their proportional relationships were observed within the adult plasma for either sex (Fig. 4i-l).

\section{Preconception paternal alcohol exposure associates with long-term alterations in immune signaling within the offspring}

Clinical studies of small-for-gestational-age neonates have associated alterations in key inflammatory markers with increased hepatic fibrosis [112, 113]. However, the mechanistic basis underlying these abnormalities has been challenging to decipher. Liver $X$ receptors $(L X R s)$ are known to modulate numerous aspects of hepatic cholesterol metabolism but have also been found to modulate immune and inflammatory responses in tissue resident macrophages [114]. Specifically, activation of $L X R / R X R$ and $F X R / R X R$ pathways suppresses tissue inflammatory responses via $N F K-B$ signaling and block the downstream release of multiple cytokine signaling molecules [115].
We, therefore, assayed the liver, pancreas and plasma for alterations in $I L 1 B, I L 6, I N F \gamma$ and $T N F \alpha$, which are all established markers of inflammation linked to $L X R$ and $N F K b$ signaling $[116,117]$. In the liver, a 15\% decrease in $I L 1 B$ and a $60 \%$ decrease in IL6 were identified in both male and female offspring, while no alterations in INFG and TNFa were observed (Fig. $5 \mathrm{a}-\mathrm{d}$ ). In the pancreas, the male offspring of alcohol-exposed sires displayed a 40\% decrease in the levels of IL1B, IL6 and TNF $\alpha$, while levels of INF $\gamma$ were similar to the controls (Fig. $5 \mathrm{e}-\mathrm{h}$ ). No differences in any of the measured cytokines were observed in the pancreas of female offspring (Fig. $5 \mathrm{e}-\mathrm{h}$ ). In the plasma, only IL6 could be detected and no significant differences were observed in either males or females (Fig. 5i). These results are similar to previous clinical observations of FASD adolescents, which have also reported immune suppression within this patient group [7-9].

\section{Preconception alcohol exposure does not impact the regulation of imprinted genes}

This study utilized two strains of mice carrying distinct single nucleotide polymorphisms within both the promoter regions and messenger RNAs of multiple genes. When using F1 hybrid crosses between the B6(CAST7) strain and a C57BL/6J strain, we can distinguish maternal and paternal alleles using C57BL/6(Cast7) and C57BL/6J polymorphisms. Using informatic approaches, we mined our RNA sequence datasets to determine if any imprinted genes exhibited abnormal bi-allelic expression (Table 1). We were able to identify exclusively paternal expression for Peg3, exclusively maternal expression for Snrpn and bi-allelic expression of Ube3a, which is only imprinted in the brain. None of the candidate genes examined displayed any detectable abnormalities in imprinted gene expression, and no candidate genes were identified as differentially expressed in the RNA-seq dataset.

\section{Discussion}

Our group recently reported sex-specific patterns of fetal growth restriction in a mouse model of preconception male ethanol exposure [58]. This growth restriction predominantly impacted the female offspring of ethanolexposed sires and was accompanied by a $12 \%$ decrease in placental efficiency, abnormal placental cholesterol transport and altered markers of hepatic fibrosis within the fetal liver. The aim of the present study was to determine whether these paternally inherited abnormalities cause any long-term impacts on the growth and metabolic health of the offspring. Here, we report that chronic paternal ethanol exposure associated with a prolonged period of fetal gestation and an increased incidence of 


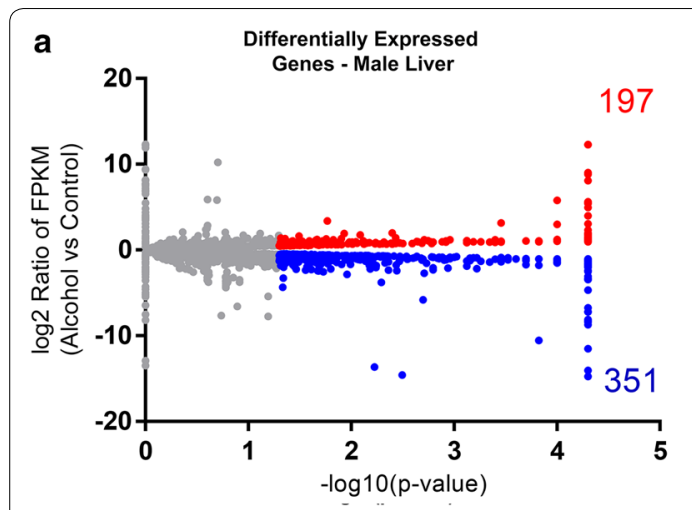

c

\begin{tabular}{|l|l|l|}
\hline IPA Predicted Category & Predicted Activation & $\rho$-value \\
\hline FXR/RXR Activation & Increase & $1.31 \mathrm{E}-08$ \\
\hline Cholesterol Biosynthesis & Decrease & $2.07 \mathrm{E}-07$ \\
\hline LXR/RXR Activation & Increase & $5.50 \mathrm{E}-07$ \\
\hline
\end{tabular}

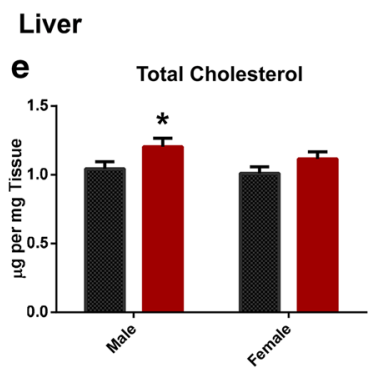

Plasma
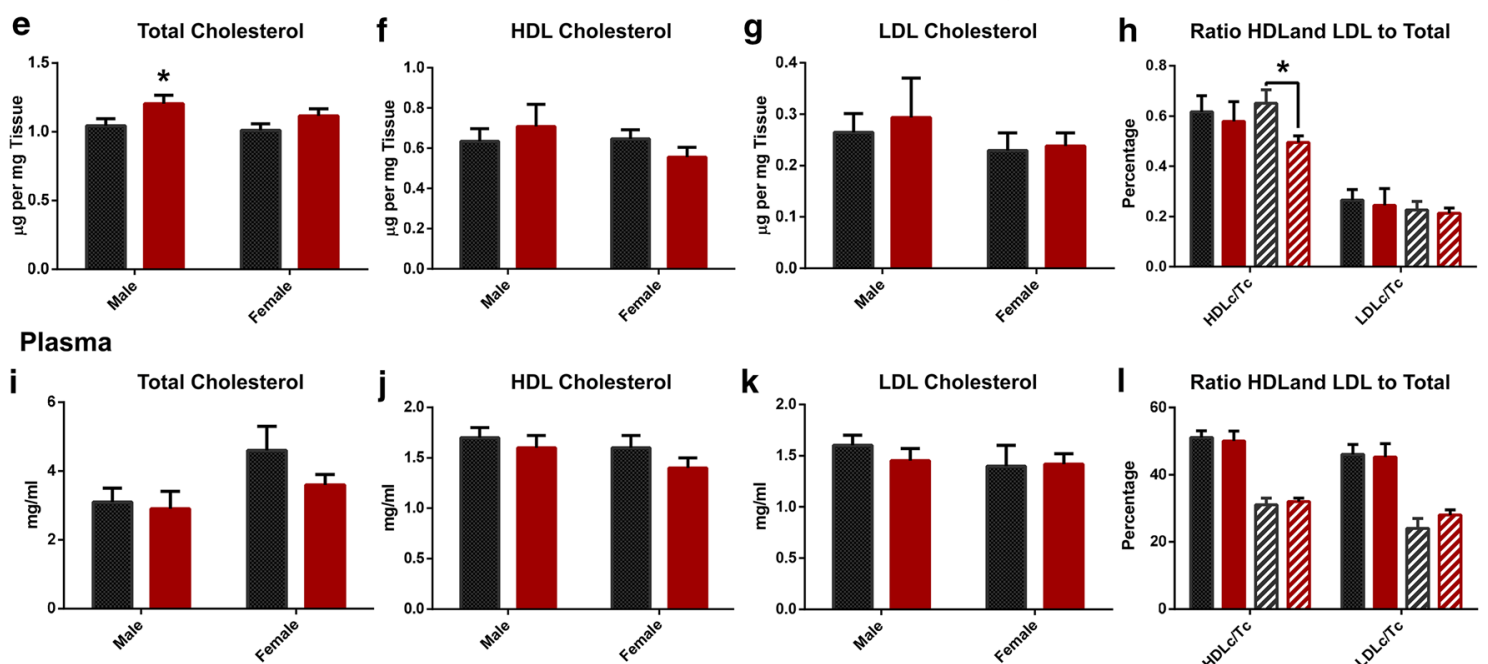

b

Pooled Comparison

Alcohol 1

Alcohol 2

Alcohol 3
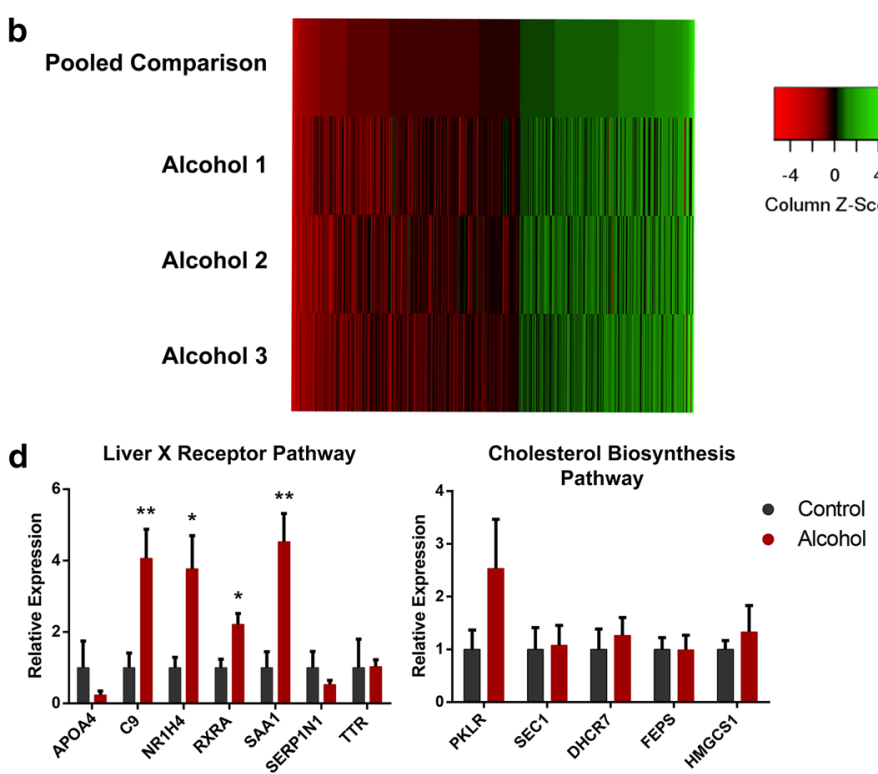

- Control

Alcohol
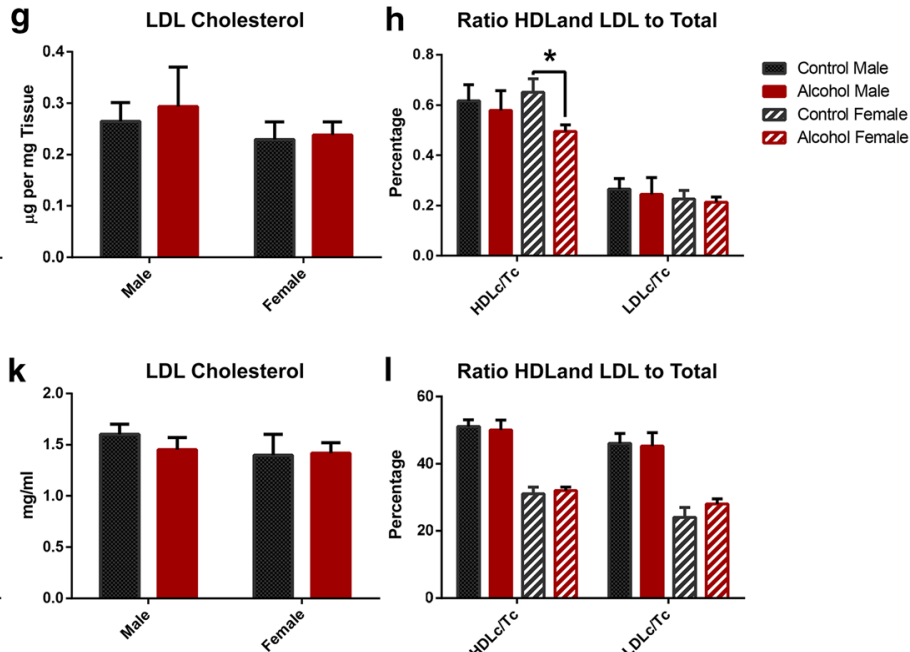

Fig. 4 Comparison of the hepatic transcriptome between the adult offspring of ethanol-exposed and control males. a Volcano plot displaying differences in gene expression between adult male offspring sired by ethanol-exposed and control fathers $(n=3$, cutoff $q=0.05)$. $\mathbf{b}$ Heatmap depicting the differentially expressed genes between the pooled control offspring and each of the three offspring of the alcohol-exposed males. c Top three categories identified using Ingenuity Pathway Analysis. d RT-qPCR validation of candidate genes related to the identified FXR/RXR, FXR/RXR and cholesterol biosynthesis pathways in the adult male liver $(n=8)$. Levels of hepatic e total cholesterol, $\mathbf{f}$ high-density lipoprotein and $\mathbf{g}$ low-density lipoprotein cholesterol esters within the liver of male and female offspring sired by ethanol-exposed and control fathers $(n=8)$. $\mathbf{h}$ Proportional ratios of $\mathrm{HDL}$ cholesterol to total cholesterol and $\mathrm{LDL}$ cholesterol to total cholesterol in liver samples derived from the male and female offspring of ethanol-exposed and control males $(n=8)$. Quantification of $\mathbf{i}$ total cholesterol, $\mathbf{j}$ high-density lipoprotein and $\mathbf{k}$ low-density lipoprotein cholesterol esters within the plasma of male and female offspring sired by ethanol-exposed and control fathers $(n=8)$. I Proportional ratios of HDL cholesterol to total cholesterol and LDL cholesterol to total cholesterol in plasma derived from the male and female offspring of ethanol-exposed and control males $(n=8)$. For RT-qPCR analyses, measured Ct values were normalized to the geometric mean of transcripts encoding Ywhaz, Hprt and Mrp/1, and graphed relative to the control treatment. Graphs represent independent replicates, with two independent RT reactions and three RT-qPCR measurements for each RT. Data were analyzed using either an unpaired $t$ test, arcsine transformed and an unpaired $t$ test with Welch's correction applied or used in a two-way ANOVA followed by Sidak post hoc analysis. Error bars represent SEM * $p<0.05$ and ${ }^{* *} p<0.01$ (comparisons between alcohol and control preconception treatments)

intrauterine growth restriction, which affected the male offspring to a greater extent than the females. In the male offspring, these growth deficits persisted into adult life and associated with insulin hypersensitivity, increased markers of hepatic fibrosis and alterations in immune signaling.

How preconception paternal ethanol exposure leads to the sequelae described above is not understood. We 


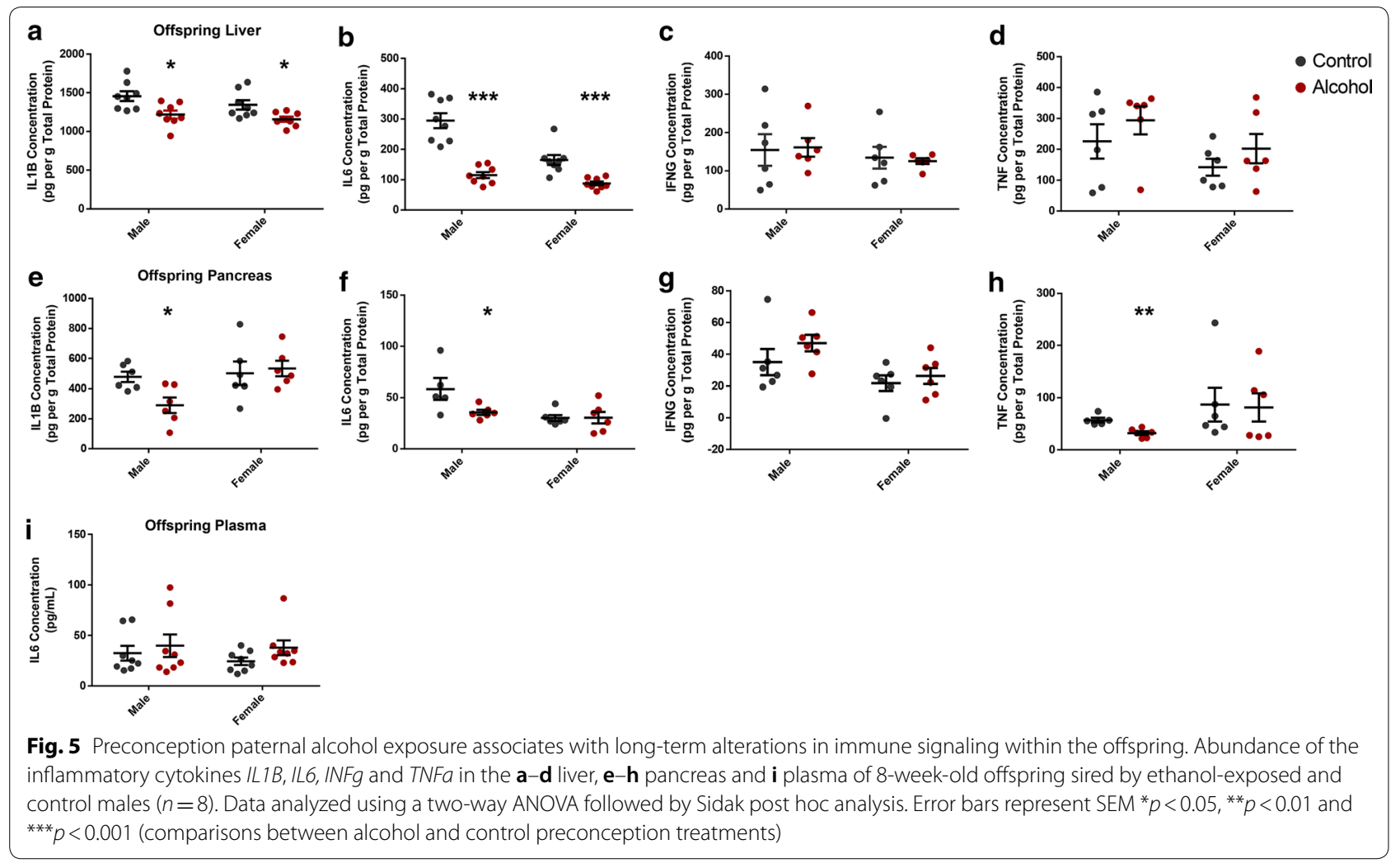

Table 1 Abundance of B6(CAST7) and C57BL/6J polymorphisms identified within select imprinted genes

\begin{tabular}{|c|c|c|c|c|c|c|c|c|}
\hline Gene & SNP location & $\mathrm{C} 57 \mathrm{BL} / 6 \mathrm{~J}$ & Control 1 & Control 2 & Control 3 & Alcohol 1 & Alcohol 2 & Alcohol 3 \\
\hline Ascl2 & chr7:142,968,971 & G & ND & ND & ND & ND & ND & ND \\
\hline Cdkn1c & chr7:143,460,109 & A & $A / 6$ & $A / 6$ & $A / 7$ & $A / 10$ & $A / 3$ & $A / 10$ \\
\hline Den & No SNP found & & ND & ND & ND & ND & ND & ND \\
\hline Dlk1 & chr12:109,460,379 & A & ND & ND & $A / 1$ & ND & ND & ND \\
\hline Gatm & chr2:122,594,926 & C & ND & ND & ND & ND & ND & ND \\
\hline Gnas & No SNP found & & ND & ND & ND & ND & ND & ND \\
\hline Grb10 & chr11:11,954,907 & A & $A / 1$ & ND & ND & ND & ND & ND \\
\hline Gt12 & chr12:109,545,837 & A & $A / 1$ & $A / 1$ & ND & ND & ND & ND \\
\hline H19 & chr7:142,577,095 & $\mathrm{T}$ & ND & ND & $\mathrm{T} / 1$ & $\mathrm{~T} / 1$ & $\mathrm{~T} / 1 \mathrm{C} / 1$ & ND \\
\hline $\operatorname{lgf2}(1)$ & chr7:142,652,037 & G & ND & ND & ND & ND & ND & ND \\
\hline $\operatorname{lgf2}(2)$ & chr7:142,652,936 & $C$ & ND & ND & ND & ND & $\mathrm{G} / 2$ & ND \\
\hline $\operatorname{lgf} 2 r$ & chr17:12,682,709 & C & $C / 64$ & $C / 116$ & $C / 171$ & $C / 126$ & $C / 67$ & $\mathrm{C} / 87$ \\
\hline Mest & chr6:30,747,382 & A & $\mathrm{A} / 2$ & ND & ND & ND & ND & $\mathrm{A} / 1$ \\
\hline $\mathrm{Ndn}$ & chr7:62,348,457 & $\mathrm{T}$ & $\mathrm{C} / 2$ & $C / 1$ & $C / 1$ & ND & ND & ND \\
\hline Peg3 & chr7:6,706,217 & G & $\mathrm{T} / 4$ & $\mathrm{~T} / 12$ & $\mathrm{~T} / 5$ & $\mathrm{~T} / 2$ & $\mathrm{~T} / 8$ & $\mathrm{~T} / 14$ \\
\hline Sgce & chr6:4,717,926 & $\mathrm{T}$ & $\mathrm{T} / 5$ & $\mathrm{~T} / 4$ & $\mathrm{~T} / 1$ & $\mathrm{~T} / 3$ & ND & $\mathrm{T} / 4$ \\
\hline Slc38a4 & chr15:96,995,974 & C & $\mathrm{C} / 89 \mathrm{~A} / 1$ & $\mathrm{C} / 78 \mathrm{~A} / 1$ & $C / 26$ & $\mathrm{C} / 117 \mathrm{~A} / 1$ & $\mathrm{C} / 74 \mathrm{~A} / 1$ & $\mathrm{C} / 72$ \\
\hline Snrpn & chr7:59,983,415 & $\mathrm{T}$ & $\mathrm{T} / 49$ & $\mathrm{~T} / 76$ & $\mathrm{~T} / 120$ & $\mathrm{~T} / 94$ & $\mathrm{~T} / 48$ & $\mathrm{~T} / 72$ \\
\hline Ube3a & chr7:59,228,878 & $\mathrm{T}$ & $\mathrm{T} / 7 \mathrm{C} / 5$ & $\mathrm{~T} / 8 \mathrm{C} / 8$ & $\mathrm{~T} / 3 \mathrm{C} / 5$ & $\mathrm{~T} / 16 \mathrm{C} / 10$ & $\mathrm{~T} / 7 \mathrm{C} / 9$ & $\mathrm{~T} / 6 \mathrm{C} / 3$ \\
\hline Zac1 & chr10:13,128,934 & G & $\mathrm{G} / 1$ & $\mathrm{G} / 5$ & $\mathrm{G} / 3$ & $\mathrm{G} / 3$ & ND & $\mathrm{G} / 1$ \\
\hline Zim1 & chr7:6,675,637 & A & ND & ND & ND & ND & ND & ND \\
\hline
\end{tabular}

The abundance of B6(CAST7) and C57BL/6J polymorphisms within the RNA sequencing profiles of the adult liver were compared between the offspring of males exposed to the two preconception treatments 
suspect that similar to other models of altered developmental programming, ethanol-induced disruptions in the sperm-inherited epigenetic program alter the formation or function of the placenta, which leads to long-term alterations in developmental programming within the offspring [26-28]. In our model, we observed a $7 \%$ decrease in the weight of only the female offspring at gestational day 14.5 [58], while 1 week after birth, both the male and female offspring display significant growth restriction (25\% in males $15 \%$ in females). These observations indicate that the large majority of growth restriction predominantly occurs during the later phases of pregnancy when the mouse fetus experiences a dramatic increase in growth rate [118]. This late-phase growth restriction is similar to the phenotypes reported in studies of placental-specific Insulin growth factor 2 (Igf2) loss of function, as well as prenatal nutrient restriction, which also predominantly manifests late in pregnancy $[119,120]$. In these studies, the placenta initially compensates by increasing its overall efficiency through proportional increases in the labyrinthine layer (initially) and up-regulation of System A amino acid transporters (later) [120]. However, these strategies cannot sustain fetal growth through the late phases of pregnancy, when the mouse fetus is normally growing most rapidly in absolute terms [121]. In our model, we observed decreased placental efficiency at gestational day 14.5, indicating the placenta enters the late growth phase at a functional deficit [58]. We suspect that as pregnancy proceeds, this placental dysfunction progressively gets worse, ultimately causing growth restriction and the delay in partition identified in Fig. 1. Further studies examining placental morphology and function between gestational days 16 and 19 are required to define the physiological basis of this growth restriction.

Although very few clinical studies have followed FASD children into adolescence (reviewed here [10]), the few that have, report a number of observations that share many similarities with results presented in this report. For example, a recent study examining a patient cohort from Cape Town, South Africa, followed the height, weight and head circumference of alcohol-exposed babies through to 13 years of age [5]. In this cohort, alcohol-exposed children had a growth trajectory that was significantly less than the control group at all ages examined. In our model of paternal ethanol exposure, we observed significant growth restriction at 1 week of age, which in the male offspring, persisted despite an overall increase in growth rate. Although the Cape Town study did not conduct separate analyses of males and females, other studies indicate that male FASD children have lower postnatal viability compared to females, indicating
FASD growth defects may impact boys to a greater extent than girls [122].

We observed insulin hypersensitivity in the male offspring of ethanol-exposed fathers, which correlated with long-term deficits in growth. Our observations indicate this increased response is due to heightened sensitivity of the hepatic insulin signaling pathway, although the specific molecular mechanisms by which this arises are still under investigation. Interestingly, our data are in direct contrast with both a clinical case report examining the metabolic health of FASD children [6], as well as work conducted using a rat model of prenatal maternal ethanol exposure, in which insulin resistance was observed $[123,124]$. However, in the rat model, both the male and female F2 progeny of ethanol-exposed offspring displayed hypoglycemia and hyperinsulinemic response patterns [124]. Combined with our work, these observations suggest that ethanol can program an insulin hypersensitive phenotype, which, similar to alcohol-induced disruptions to the hypothalamic-pituitary axis [79], can transmit to the next generation via the germline.

Clinical studies have shown that, even after controlling for low maternal income, maternal smoking and birthweight, newborns whose mothers drank during pregnancy have a threefold increased risk of infection compared to mothers who did not drink [9]. FASD infants exhibit an increased risk of developing upper respiratory tract infections, recurrent otitis media, pneumonia, persistent diaper rash, meningitis and gastroenteritis $[7,8]$. These deficits in immune function have been linked to alterations in the number of $\mathrm{T}$ helper $(C D 4+/$ $C D 3+)$ and $\mathrm{T}$ cytotoxic/suppressor cells $(C D S+/ C D 3+)$ [8], suggesting the processes driving systemic inflammation are blunted in these children. Our studies examining the offspring of ethanol-exposed males identified alterations in hepatic $L X R$ signaling, which, through the activity of $N F K b$, is a potent suppressor of multiple cytokine signaling pathways $[114,115]$. Consistent with these observations, we identified tissue-specific reductions in multiple $N F K b$ regulated genes (IL1B, IL6 and TNFa) within the liver and pancreas but not in the plasma. It is unclear if the reductions in immune signaling observed in our model have any relevance to the enhanced predisposition of FASD children to postnatal infection; however, programmed alterations in systemic inflammation appear to be a common theme emerging in other models of developmental programming [125]. Additional studies are needed to determine how preconception paternal ethanol exposure influences the inflammatory stress response.

Consistent with previous studies [126], placental dysfunction occurring late in gestation predominantly affected the long-term health of the male fetus, while 
the female offspring were better able to recover. These observations suggest that females are better able to compensate for late-stage insults than males. Interestingly, while hepatic fibrosis is one of the defining symptoms of alcoholic liver disease in adults [127], three isolated case reports have also identified a similar condition in FASD children [128-130]. Our previous studies of the fetal liver identified alterations in the transcription of candidate genes participating in the genetic pathways regulating hepatic fibrosis and stellate cell activation [58]. Although found in both the male and female offspring of ethanolexposed sires, this signature was diametrically opposite between the sexes; males displayed an up-regulation of pro-fibrotic genes, while females suppressed this pathway. In the liver, $72 \%$ of genes are expressed in a sexually dimorphic manner and importantly, half of the candidate gene identified in this study follow this pattern [131]. Therefore, sex-specific differences in patterns of hepatic gene expression may explain the contrasting outcomes between the male and female offspring. Importantly, the persistence of this signature in the adult male liver, along with the increased hydroxyproline content, suggests that preconception paternal alcohol exposure may predispose the offspring to hepatic dysfunction and susceptibility to liver disease. If true, this would significantly enhance our understanding of the mechanisms of inheritance at work in the development and progression of alcoholic liver disease. Additional studies are necessary to determine the importance this pro-fibrotic signature has in hepatic disease pathogenesis.

Finally, although we were unable to validate the differential expression of genes participating in the cholesterol biosynthesis pathway, we did observe a modest increase in total cholesterol levels in the male offspring of alcohol-exposed sires and a proportional reduction in the ratio of high-density lipoproteins to total cholesterol in the female offspring. The failure to identify changes in cholesterol-related transcripts is likely reflective of the variability of this model, which unlike a genetic model is more prone to produce a subset of offspring that are highly affected while others exhibit a more modest phenotype. Indeed, although select collagen subtypes were present in our RNA-seq datasets, fibrosis did not emerge as an enriched pathway, indicating this phenotype is also highly variable. Future studies will explore the impact the stress of a high-fat diet has on the offspring of alcoholexposed fathers and will help determine both the penetrance of the metabolic phenotypes and the extent of the sexual dimorphism in this preconception model of exposure.

One potential confound to this study is the use of the $0.066 \%(\mathrm{w} / \mathrm{v})$ Sweet'N Low in both the control and alcohol preconception treatments, which was used to promote the consistent consumption of ethanol [90]. The gut contains glucose receptors that are stimulated by artificial sweeteners causing the release of incretin peptide hormones, which have a significant role in glucose homeostasis, metabolic control and proper $\beta$-cell function [132]. Artificial sweeteners also influence the intestinal microbiota and alter metabolic function indirectly [95]. Therefore, it is possible that some of the effects are the result of metabolic disturbances in the sires. However, we did not observe any differences in weight gain between the preconception treatments and neither group displayed an obese phenotype. In addition, genetic differences unique to the C57BL/6(Cast7) and C57BL/6J cross may influence the observed phenotypes. However, the ability to informatically distinguish the maternal and paternal alleles allowed us to examine imprinted gene expression, which is disrupted in other models of developmental programming [133]. Future studies will focus on implementing an exposure paradigm that does not involve the use of artificial sweeteners and repeating these observations using both a pure C57BL/6J cross and an outbred line.

\section{Conclusions}

Non-syndromic developmental defects are multifactorial and are hypothesized to result from the complex interplay between genetic, epigenetic, environmental and lifestyle factors [134, 135]. Our data further support the epidemiological association between paternal alcohol consumption and deficits in child development [33-45, 136]. Specifically, our study associates chronic preconception paternal ethanol exposure with prenatal/ postnatal growth restriction, sex-specific alterations in long-term metabolic function, immune dysfunction and hepatic fibrosis. As discussed above, these pathologies have been observed in long-term studies of FASD children, indicating paternal alcohol use is a relevant factor in the etiology of this disorder. Given the fact that male alcohol consumption far exceeds that of women [92, 93], we should more carefully consider the preconception lifestyle choices of the birth-father in the development of this condition and broaden our educational outreach concerning the teratogenic actions of this agent.

\section{Additional files}

Additional file 1. Primer sequences used in RT-qPCR analyses.

Additional file 2. Supporting information for Figure 1. A) Datasets discussed in Figure 1 are presented in table form. B) Formula used to calculate the IUGR ratio. C) Formula used to calculate growth rate of the offspring. 


\begin{abstract}
Abbreviations
FASDs: fetal alcohol spectrum disorders; LXR: LiverX receptor; RXR: RetinoidX receptor; FXR: FarnesoidX receptor; IUGR: intrauterine growth restriction; AKT: protein kinase B; FPKM: fragments per kilobase of exon per million fragments mapped; GPCR: real time quantitative polymerase chain reaction; RT-qPCR: reverse transcriptase quantitative polymerase chain reaction; Ct: cycle threshold; Ywhaz: 3-monooxygenase/tryptophan 5-monooxygenase activation protein zeta; Mrpl1: mitochondrial ribosomal protein L1; Hprt: hypoxanthine phosphoribosyl transferase; NAFLD: non-alcoholic fatty liver disease; TGF-B: transforming growth factor-beta; NFkB: nuclear factor-kappa-B; IL-6: interleukin-6; IL1B: interleukin-1 beta; INF-g: interferon gamma; TNFa: tumor necrosis factor alpha; C9: complement C9; Smad2: mothers against DPP homolog 2; Smad4: mothers against DPP homolog 4; Col5a1: collagen type $V$ alpha 1 chain; Col6a1: collagen type VI alpha 1 chain; Col18a1: collagen type XVIII alpha 1 chain; Saa1: serum amyloid A1; Nh1 r4: farnesoid X-activated receptor; Peg3: paternally expressed gene 3; Snrpn: small nuclear ribonucleoprotein polypeptide N; Ube3a: ubiquitin protein ligase E3A; Igf2: insulin growth factor 2.
\end{abstract}

\section{Authors' contributions}

RCC and MCG designed the experiments and analyzed the data; RCC, HW, YB and MCG performed the research; MCG wrote the paper. All authors read and approved the final manuscript.

\section{Competing interests}

The authors declare that they have no competing interests.

\section{Availability of data and materials}

The RNA sequencing datasets generated in this study have been deposited in the NCBI Gene Expression Omnibus (GEO) repository and can be accessed under the accession number GSE117559.

\section{Consent for publication}

Not applicable.

\section{Ethics approval and consent to participate}

All experiments were conducted under AUP 2017-0308 and approved by the Texas A\&M University IACUC.

\section{Funding}

This work was supported by the National Institutes of Health, Grant 1R21AA022484 and the Texas A\&M Triads for Transformation multidisciplinary seed-grant.

\section{Publisher's Note}

Springer Nature remains neutral with regard to jurisdictional claims in published maps and institutional affiliations.

Received: 20 July 2018 Accepted: 17 January 2019

Published online: 22 January 2019

\section{References}

1. Hoyme HE, May PA, Kalberg WO, Kodituwakku P, Gossage JP, Trujillo PM, et al. A practical clinical approach to diagnosis of fetal alcohol spectrum disorders: clarification of the 1996 institute of medicine criteria. Pediatrics. 2005;115(1):39-47.

2. Riley EP, Infante MA, Warren KR. Fetal alcohol spectrum disorders: an overview. Neuropsychol Rev. 2011;21(2):73-80.

3. Day NL, Leech SL, Richardson GA, Cornelius MD, Robles N, Larkby C. Prenatal alcohol exposure predicts continued deficits in offspring size at 14 years of age. Alcohol Clin Exp Res. 2002;26(10):1584-91.

4. Burd L, Roberts D, Olson M, Odendaal H. Ethanol and the placenta: a review. J Matern Fetal Neonatal Med. 2007;20(5):361-75.

5. Carter RC, Jacobson JL, Sokol RJ, Avison MJ, Jacobson SW. Fetal alcoholrelated growth restriction from birth through young adulthood and moderating effects of maternal prepregnancy weight. Alcohol Clin Exp Res. 2013;37(3):452-62.
6. Castells S, Mark E, Abaci F, Schwartz E. Growth retardation in fetal alcohol syndrome. Unresponsiveness to growth-promoting hormones. Dev Pharmacol Ther. 1981;3(4):232-41.

7. Johnson S, Knight R, Marmer DJ, Steele RW. Immune deficiency in fetal alcohol syndrome. Pediatr Res. 1981;15(6):908-11.

8. Oleson DR, Magee RM, Donahoe RM, Falek A, Coles CD. Immunity and prenatal alcohol exposure. A pilot study in human adolescents. Adv Exp Med Biol. 1998;437:255-64.

9. Gauthier TW, Drews-Botsch C, Falek A, Coles C, Brown LA. Maternal alcohol abuse and neonatal infection. Alcohol Clin Exp Res. 2005;29(6):1035-43.

10. Moore EM, Riley EP. What happens when children with fetal alcohol spectrum disorders become adults? Curr Dev Disord Rep. 2015;2(3):219-27.

11. Thanh NX, Jonsson E. Life expectancy of people with fetal alcohol syndrome. J Popul Ther Clin Pharmacol. 2016;23(1):e53-9.

12. Lunde ER, Washburn SE, Golding MC, Bake S, Miranda RC, Ramadoss J. Alcohol-Induced developmental origins of adult-onset diseases. Alcohol Clin Exp Res. 2016;40(7):1403-14.

13. Lussier AA, Weinberg J, Kobor MS. Epigenetics studies of fetal alcohol spectrum disorder: where are we now? Epigenomics. 2017;9(3):291-311.

14. Ernhart CB, Wolf AW, Linn PL, Sokol RJ, Kennard MJ, Filipovich HF. Alcohol-related birth defects: syndromal anomalies, intrauterine growth retardation, and neonatal behavioral assessment. Alcohol Clin Exp Res. 1985;9(5):447-53.

15. Padmanabhan R, Hameed MS. Effects of acute doses of ethanol administered at pre-implantation stages on fetal development in the mouse. Drug Alcohol Depend. 1988:22(1-2):91-100.

16. Gundogan F, Elwood G, Longato L, Tong M, Feijoo A, Carlson RI, et al. Impaired placentation in fetal alcohol syndrome. Placenta. 2008;29(2):148-57.

17. Shukla PK, Sittig LJ, Ullmann TM, Redei EE. Candidate placental biomarkers for intrauterine alcohol exposure. Alcohol Clin Exp Res. 2011;35(3):559-65.

18. Boehm G, Müller DM, Teichmann B, Krumbiegel P. Influence of intrauterine growth retardation on parameters of liver function in low birth weight infants. Eur J Pediatr. 1990;149(6):396-8.

19. Nobili V, Marcellini M, Marchesini G, Vanni E, Manco M, Villani A, Bugianesi E. Intrauterine growth retardation, insulin resistance, and nonalcoholic fatty liver disease in children. Diabetes Care. 2007;30(10):2638-40.

20. Pylipow M, Spector LG, Puumala SE, Boys C, Cohen J, Georgieff MK. Early postnatal weight gain, intellectual performance, and body mass index at 7 years of age in term infants with intrauterine growth restriction. J Pediatr. 2009;154(2):201-6.

21. Alisi A, Panera N, Agostoni C, Nobili V. Intrauterine growth retardation and nonalcoholic fatty liver disease in children. Int J Endocrinol. 2011;2011:269853.

22. Morsing E, Asard M, Ley D, Stjernqvist K, Marsál K. Cognitive function after intrauterine growth restriction and very preterm birth. Pediatrics. 2011;127(4):e874-82.

23. Løhaugen GC, Østgård HF, Andreassen S, Jacobsen GW, VikT, Brubakk AM, et al. Small for gestational age and intrauterine growth restriction decreases cognitive function in young adults. J Pediatr. 2013;163(2):447-53.

24. Longo S, Bollani L, Decembrino L, Comite AD, Angelini M, Stronati M. Short-term and long-term sequelae in intrauterine growth retardation (IUGR). J Matern Fetal Neonatal Med. 2013;26(3):222-5.

25. von Beckerath A, Kollmann M, Rotky-Fast C, Karpf E, Lang U, Klaritsch P. Perinatal complications and long-term neurodevelopmental outcome of infants with intrauterine growth restriction. Am J Obstet Gynecol. 2013;208(2):130.e1-6

26. Lane M, Robker RL, Robertson SA. Parenting from before conception. Science. 2014;345(6198):756-60.

27. Rando OJ, Simmons RA. I'm eating for two: parental dietary effects on offspring metabolism. Cell. 2015;161(1):93-105.

28. Kalisch-Smith J, Moritz KM. Review: Detrimental effects of alcohol exposure around conception: putative mechanisms. Biochem Cell Biol. 2017;96(2):107-16.

29. Schaefer GB, Deere D. Recognition, diagnosis and treatment of fetal alcohol syndrome. J Ark Med Soc. 2011;108(2):38-40. 
30. Schagdarsurengin $U$, Steger K. Epigenetics in male reproduction: effect of paternal diet on sperm quality and offspring health. Nat Rev Urol. 2016;13(10):584-95.

31. Finegersh A, Rompala GR, Martin DI, Homanics GE. Drinking beyond a lifetime: new and emerging insights into paternal alcohol exposure on subsequent generations. Alcohol. 2015;49(5):461-70.

32. Day J, Savani S, Krempley BD, Nguyen M, Kitlinska JB. Influence of paternal preconception exposures on their offspring: through epigenetics to phenotype. Am J Stem Cells. 2016;5(1):11-8.

33. Tarter RE, Hegedus AM, Goldstein G, Shelly C, Alterman Al. Adolescent sons of alcoholics: neuropsychological and personality characteristics. Alcohol Clin Exp Res. 1984;8(2):216-22.

34. Pihl RO, Peterson J, Finn P. Inherited predisposition to alcoholism: characteristics of sons of male alcoholics. J Abnorm Psychol. 1990;99(3):291-301

35. Ozkaragoz T, Satz P, Noble EP. Neuropsychological functioning in sons of active alcoholic, recovering alcoholic, and social drinking fathers. Alcohol. 1997;14(1):31-7.

36. Knopik VS, Sparrow EP, Madden PA, Bucholz KK, Hudziak JJ, Reich W, et al. Contributions of parental alcoholism, prenatal substance exposure, and genetic transmission to child ADHD risk: a female twin study. Psychol Med. 2005;35(5):625-35.

37. Disney ER, lacono W, McGue M, Tully E, Legrand L. Strengthening the case: prenatal alcohol exposure is associated with increased risk for conduct disorder. Pediatrics. 2008;122(6):e1225-30.

38. Cservenka A, Fair DA, Nagel BJ. Emotional processing and brain activity in youth at high risk for alcoholism. Alcohol Clin Exp Res. 2014;38(7):1912-23.

39. Gabrielli WF, Mednick SA. Intellectual performance in children of alcoholics. J Nerv Ment Dis. 1983;171(7):444-7.

40. Hegedus AM, Alterman Al, Tarter RE. Learning achievement in sons of alcoholics. Alcohol Clin Exp Res. 1984;8(3):330-3.

41. Ervin CS, Little RE, Streissguth AP, Beck DE. Alcoholic fathering and its relation to child's intellectual development: a pilot investigation. Alcohol Clin Exp Res. 1984;8(4):362-5.

42. Weinberg NZ. Cognitive and behavioral deficits associated with parental alcohol use. J Am Acad Child Adolesc Psychiatry. 1997;36(9):1177-86.

43. Haugland BS. Paternal alcohol abuse: relationship between child adjustment, parental characteristics, and family functioning. Child Psychiatry Hum Dev. 2003;34(2):127-46.

44. Little RE, Sing CF. Father's drinking and infant birth weight: report of an association. Teratology. 1987;36(1):59-65.

45. Zuccolo L, DeRoo LA, Wills AK, Davey Smith G, Suren P, Roth C, et al. Preconception and prenatal alcohol exposure from mothers and fathers drinking and head circumference: results from the norwegian motherchild study (moba). Sci Rep. 2016;7:39535.

46. Xia R, Jin L, Li D, Liang H, Yang F, Chen J, et al. Association between paternal alcohol consumption before conception and anogenital distance of offspring. Alcohol Clin Exp Res. 2018:42(4):735-42.

47. Windham GC, Fenster L, Hopkins B, Swan SH. The association of moderate maternal and paternal alcohol consumption with birthweight and gestational age. Epidemiology. 1995;6(6):591-7.

48. Gribovski A, Bygren LO, Svartbo B, Magnus P. Housing conditions, perceived stress, smoking, and alcohol: determinants of fetal growth in northwest russia. Acta Obstet Gynecol Scand. 2004;83(12):1159-66.

49. Abel EL. Alcohol consumption does not affect fathers but does affect their offspring in the forced swimming test. Pharmacol Toxicol. 1991;68(1):68-9.

50. Bielawski DM, Abel EL. Acute treatment of paternal alcohol exposure produces malformations in offspring. Alcohol. 1997;14(4):397-401.

51. Ledig M, Misslin R, Vogel E, Holownia A, Copin JC, Tholey G. Paternal alcohol exposure: developmental and behavioral effects on the offspring of rats. Neuropharmacology. 1998;37(1):57-66.

52. Bielawski DM, Zaher FM, Svinarich DM, Abel EL. Paternal alcohol exposure affects sperm cytosine methyltransferase messenger RNA levels. Alcohol Clin Exp Res. 2002;26(3):347-51.

53. Jamerson PA, Wulser MJ, Kimler BF. Neurobehavioral effects in rat pups whose sires were exposed to alcohol. Brain Res Dev Brain Res. 2004;149(2):103-11.

54. Meek LR, Myren K, Sturm J, Burau D. Acute paternal alcohol use affects offspring development and adult behavior. Physiol Behav. 2007:91(1):154-60.
55. Ouko LA, Shantikumar K, Knezovich J, Haycock P, Schnugh DJ, Ramsay M. Effect of alcohol consumption on cpg methylation in the differentially methylated regions of $\mathrm{H} 19$ and IG-DMR in male gametes: implications for fetal alcohol spectrum disorders. Alcohol Clin Exp Res. 2009;33(9):1615-27.

56. Knezovich JG, Ramsay M. The effect of preconception paternal alcohol exposure on epigenetic remodeling of the h19 and rasgrf1 imprinting control regions in mouse offspring. Front Genet. 2012;3:10.

57. Lee HJ, Ryu J, Choi NY, Park YS, Kim YI, Han DW, et al. Transgenerational effects of paternal alcohol exposure in mouse offspring. Anim Cells Syst. 2013;17(6):429-34.

58. Chang RC, Skiles WM, Chronister SS, Wang H, Sutton Gl, Bedi YS, et al. DNA methylation-independent growth restriction and altered developmental programming in a mouse model of preconception male alcohol exposure. Epigenetics. 2017;12(10):841-53.

59. Anway MD, Cupp AS, Uzumcu M, Skinner MK. Epigenetic transgenerational actions of endocrine disruptors and male fertility. Science. 2005;308(5727):1466-9.

60. Carone BR, Fauquier L, Habib N, Shea JM, Hart CE, Li R, et al. Paternally induced transgenerational environmental reprogramming of metabolic gene expression in mammals. Cell. 2010;143(7):1084-96.

61. Ng SF, Lin RC, Laybutt DR, Barres R, Owens JA, Morris MJ. Chronic highfat diet in fathers programs $\beta$-cell dysfunction in female rat offspring. Nature. 2010:467(7318):963-6.

62. Radford EJ, Isganaitis E, Jimenez-Chillaron J, Schroeder J, Molla M, Andrews $\mathrm{S}$, et al. An unbiased assessment of the role of imprinted genes in an intergenerational model of developmental programming. PLoS Genet. 2012;8(4):e1002605

63. Zeybel M, Hardy T, Wong YK, Mathers JC, Fox CR, Gackowska A, et al. Multigenerational epigenetic adaptation of the hepatic wound-healing response. Nat Med. 2012;18(9):1369-77.

64. Fullston T, Ohlsson Teague EM, Palmer NO, DeBlasio MJ, Mitchell M, Corbett $M$, et al. Paternal obesity initiates metabolic disturbances in two generations of mice with incomplete penetrance to the F2 generation and alters the transcriptional profile of testis and sperm microrna content. FASEB J. 2013;27(10):4226-43.

65. Lambrot R, Xu C, Saint-Phar S, Chountalos G, Cohen T, Paquet M, et al. Low paternal dietary folate alters the mouse sperm epigenome and is associated with negative pregnancy outcomes. Nat Commun. 2013:4:2889.

66. Gapp K, Jawaid A, Sarkies P, Bohacek J, Pelczar P, Prados J, et al. Implication of sperm rnas in transgenerational inheritance of the effects of early trauma in mice. Nat Neurosci. 2014;17(5):667-9.

67. Dias BG, Ressler KJ. Parental olfactory experience influences behavior and neural structure in subsequent generations. Nat Neurosci. 2014;17(1):89-96.

68. Radford EJ, Ito M, Shi H, Corish JA, Yamazawa K, Isganaitis E, et al. In utero effects. In utero undernourishment perturbs the adult sperm methylome and intergenerational metabolism. Science. 2014;345(6198):1255903.

69. Wei Y, Yang CR, Wei YP, Zhao ZA, Hou Y, Schatten H, Sun QY. Paternally induced transgenerational inheritance of susceptibility to diabetes in mammals. Proc Natl Acad Sci USA. 2014·111(5):1873-8.

70. Shea JM, Serra RW, Carone BR, Shulha HP, Kucukural A, Ziller MJ, et al. Genetic and epigenetic variation, but not diet, shape the sperm methylome. Dev Cell. 2015;35(6):750-8.

71. Terashima M, Barbour S, Ren J, Yu W, Han Y, Muegge K. Effect of high fat diet on paternal sperm histone distribution and male offspring liver gene expression. Epigenetics. 2015;10(9):861-71.

72. Sharma U, Conine CC, Shea JM, Boskovic A, Derr AG, Bing XY, et al. Biogenesis and function of trna fragments during sperm maturation and fertilization in mammals. Science. 2016;351(6271):391-6.

73. Chen Q, Yan M, Cao Z, Li X, Zhang Y, Shi J, et al. Sperm tsrnas contribute to intergenerational inheritance of an acquired metabolic disorder. Science. 2016;351(6271):397-400.

74. Donkin I, Versteyhe S, Ingerslev LR, Qian K, Mechta M, Nordkap L, et al. Obesity and bariatric surgery drive epigenetic variation of spermatozoa in humans. Cell Metab. 2016;23(2):369-78.

75. Esakky P, Hansen DA, Drury AM, Felder P, Cusumano A, Moley KH. Paternal exposure to cigarette smoke condensate leads to reproductive 
sequelae and developmental abnormalities in the offspring of mice. Reprod Toxicol. 2016;65:283-94.

76. Rompala GR, Mounier A, Wolfe CM, Lin Q, Lefterov I, Homanics GE. Heavy chronic intermittent ethanol exposure alters small noncoding rnas in mouse sperm and epididymosomes. Front Genet. 2018;9:32.

77. Sun W, Dong H, Becker AS, Dapito DH, Modica S, Grandl G, et al. Coldinduced epigenetic programming of the sperm enhances brown adipose tissue activity in the offspring. Nat Med. 2018;24(9):1372-83.

78. Murphy SK, Itchon-Ramos N, Visco Z, Huang Z, Grenier C, Schrott $R$, et al. Cannabinoid exposure and altered DNA methylation in rat and human sperm. Epigenetics. 2018. https://doi.org/10.1080/15592 294.2018.1554521.

79. Govorko D, Bekdash RA, Zhang C, Sarkar DK. Male germline transmits fetal alcohol adverse effect on hypothalamic proopiomelanocortin gene across generations. Biol Psychiatry. 2012;72(5):378-88.

80. Zhang X, Lan N, Bach P, Nordstokke D, Yu W, Ellis L, et al. Prenatal alcohol exposure alters the course and severity of adjuvant-induced arthritis in female rats. Brain Behav Immun. 2012;26(3):439-50

81. Gårdebjer EM, Cuffe JS, Pantaleon M, Wlodek ME, Moritz KM. Periconceptional alcohol consumption causes fetal growth restriction and increases glycogen accumulation in the late gestation rat placenta. Placenta. 2014;35(1):50-7.

82. Shen L, Liu Z, Gong J, Zhang L, Wang L, Magdalou J, et al. Prenatal ethanol exposure programs an increased susceptibility of non-alcoholic fatty liver disease in female adult offspring rats. Toxicol Appl Pharmacol. 2014;274(2):263-73.

83. Gårdebjer EM, Anderson ST, Pantaleon M, Wlodek ME, Moritz KM. Maternal alcohol intake around the time of conception causes glucose intolerance and insulin insensitivity in rat offspring, which is exacerbated by a postnatal high-fat diet. FASEB J. 2015;29(7):2690-701.

84. Gardebjer EM, Cuffe JSM, Ward LC, Steane S, Anderson ST, Dorey ES, et al. The effects of periconceptional maternal alcohol intake and a postnatal high-fat diet on obesity and liver disease in male and female rat offspring. Am J Physiol Endocrinol Metab. 2017:ajpendo002512017.

85. Raineki C, Bodnar TS, Holman PJ, Baglot SL, Lan N, Weinberg J. Effects of early-life adversity on immune function are mediated by prenatal environment: role of prenatal alcohol exposure. Brain Behav Immun. 2017:66:210-20.

86. Mann MR, Chung YG, Nolen LD, Verona RI, Latham KE, Bartolomei MS. Disruption of imprinted gene methylation and expression in cloned preimplantation stage mouse embryos. Biol Reprod. 2003;69(3):902-14.

87. Golding MC, Magri LS, Zhang L, Lalone SA, Higgins MJ, Mann MR. Depletion of Kcnq1 ot1 non-coding RNA does not affect imprinting maintenance in stem cells. Development. 2011;138(17):3667-78.

88. Chen Y, Ozturk NC, Ni L, Goodlett C, Zhou FC. Strain differences in developmental vulnerability to alcohol exposure via embryo culture in mice. Alcohol Clin Exp Res. 2011;35(7):1293-304.

89. Downing C, Johnson TE, Larson C, Leakey TI, Siegfried RN, Rafferty TM, Cooney CA. Subtle decreases in DNA methylation and gene expression at the mouse igf2 locus following prenatal alcohol exposure: effects of a methyl-supplemented diet. Alcohol. 2011;45(1):65-71.

90. Brady ML, Allan AM, Caldwell KK. A limited access mouse model of prenatal alcohol exposure that produces long-lasting deficits in hippocampal-dependent learning and memory. Alcohol Clin Exp Res. 2012;36(3):457-66.

91. Thiele TE, Crabbe JC, Boehm SL. "Drinking in the dark" (DID): a simple mouse model of binge-like alcohol intake. Curr Protoc Neurosci. 2014:68:9-49.

92. White AM, Kraus $\mathrm{CL}$, Swartzwelder H. Many college freshmen drink at levels far beyond the binge threshold. Alcohol Clin Exp Res. 2006;30(6):1006-10

93. Kanny D, Naimi TS, Liu Y, Lu H, Brewer RD. Annual total binge drinks consumed by U.S. adults, 2015. Am J Prev Med. 2018;54(4):486-96.

94. Naimi TS, Brewer RD, Mokdad A, Denny C, Serdula MK, Marks JS. Binge drinking among US adults. JAMA. 2003;289(1):70-5.

95. Suez J, Korem T, Zeevi D, Zilberman-Schapira G, Thaiss CA, Maza O, et al. Artificial sweeteners induce glucose intolerance by altering the gut microbiota. Nature. 2014;514(7521):181-6.

96. Adler ID. Comparison of the duration of spermatogenesis between male rodents and humans. Mutat Res. 1996;352(1-2):169-72.
97. Braun RE, Lee K, Schumacher JM, Fajardo MA. Molecular genetic analysis of mammalian spermatid differentiation. Recent Prog Horm Res. 1995:50:275-86.

98. Overmyer KA, Thonusin C, Qi NR, Burant CF, Evans CR. Impact of anesthesia and euthanasia on metabolomics of mammalian tissues: studies in a C57BL/6J mouse model. PLoS ONE. 2015;10(2):e0117232.

99. Dobin A, Davis CA, Schlesinger F, Drenkow J, Zaleski C, Jha S, et al. STAR: ultrafast universal rna-seq aligner. Bioinformatics. 2013;29(1):15-21.

100. Jiménez-Marín A, Collado-Romero M, Ramirez-Boo M, Arce C, Garrido JJ. Biological pathway analysis by ArrayUnlock and ingenuity pathway analysis. BMC Proc. 2009;3(Suppl 4):S6.

101. Engelbregt MJ, van Weissenbruch MM, Popp-Snijders C, Lips P, Delemarre-van de Waal HA. Body mass index, body composition, and leptin at onset of puberty in male and female rats after intrauterine growth retardation and after early postnatal food restriction. Pediatr Res. 2001;50(4):474-8.

102. Carnahan MN, Veazey KJ, Muller D, Tingling JD, Miranda RC, Golding MC. Identification of cell-specific patterns of reference gene stability in quantitative reverse-transcriptase polymerase chain reaction studies of embryonic, placental and neural stem models of prenatal ethanol exposure. Alcohol. 2013;47(2):109-20.

103. Schmittgen TD, Livak KJ. Analyzing real-time PCR data by the comparative C(T) method. Nat Protoc. 2008:3(6):1101-8.

104. Hokken-Koelega AC, De Ridder MA, Lemmen RJ, Den Hartog H, De Muinck Keizer-Schrama SM, Drop SL. Children born small for gestational age: do they catch up? Pediatr Res. 1995;38(2):267-71.

105. Simmons RA, Templeton $L$, Gertz SJ. Intrauterine growth retardation leads to the development of type 2 diabetes in the rat. Diabetes. 2001;50(10):2279-86.

106. de Rooij SR, Painter RC, Phillips DI, Osmond C, Michels RP, Godsland IF, et al. Impaired insulin secretion after prenatal exposure to the Dutch famine. Diabetes Care. 2006;29(8):1897-901.

107. Limesand SW, Rozance PJ, Zerbe GO, Hutton JC, Hay WW. Attenuated insulin release and storage in fetal sheep pancreatic islets with intrauterine growth restriction. Endocrinology. 2006;147(3):1488-97.

108. Ross MG, Beall MH. Adult sequelae of intrauterine growth restriction. Semin Perinatol. 2008;32(3):213-8.

109. Bison A, Marchal-Bressenot A, Li Z, Elamouri I, Feigerlova E, Peng L, et al. Foetal programming by methyl donor deficiency produces steatohepatitis in rats exposed to high fat diet. Sci Rep. 2016:6:37207.

110. Ding N, Hah N, Yu RT, Sherman MH, Benner C, Leblanc M, et al. BRD4 is a novel therapeutic target for liver fibrosis. Proc Natl Acad Sci USA. 2015;112(51):15713-8.

111. Ding N, Yu RT, Subramaniam N, Sherman MH, Wilson C, Rao R, et al. A vitamin $D$ receptor/SMAD genomic circuit gates hepatic fibrotic response. Cell. 2013;153(3):601-13.

112. Amarilyo G, Oren A, Mimouni FB, Ochshorn Y, Deutsch V, Mandel D. Increased cord serum inflammatory markers in small-for-gestationalage neonates. J Perinatol. 2011;31(1):30-2.

113. Delghingaro-Augusto V, Madad L, Chandra A, Simeonovic CJ, Dahlstrom JE, Nolan CJ. Islet inflammation, hemosiderosis, and fibrosis in intrauterine growth-restricted and high fat-fed sprague-dawley rats. Am J Pathol. 2014:184(5):1446-57.

114. Zelcer $\mathrm{N}$, Tontonoz $\mathrm{P}$. Liver $\mathrm{X}$ receptors as integrators of metabolic and inflammatory signaling. J Clin Invest. 2006;1 16(3):607-14.

115. Sanz MJ, Albertos F, Otero E, Juez M, Morcillo EJ, Piqueras L. Retinoid X receptor agonists impair arterial mononuclear cell recruitment through peroxisome proliferator-activated receptor- $\gamma$ activation. J Immunol. 2012;189(1):411-24.

116. Pahl HL. Activators and target genes of rel/nf-kappab transcription factors. Oncogene. 1999;18(49):6853-66.

117. Joseph SB, Castrillo A, Laffitte BA, Mangelsdorf DJ, Tontonoz P. Reciprocal regulation of inflammation and lipid metabolism by liver $X$ receptors. Nat Med. 2003:9(2):213-9.

118. Mclaren A. Genetic and environmental effects on foetal and placental growth in mice. J Reprod Fertil. 1965;9:79-98.

119. Constância M, Hemberger M, Hughes J, Dean W, Ferguson-Smith A, Fundele $\mathrm{R}$, et al. Placental-specific IGF-II is a major modulator of placental and fetal growth. Nature. 2002;417(6892):945-8. 
120. Coan PM, Vaughan OR, Sekita Y, Finn SL, Burton GJ, Constancia M, Fowden AL. Adaptations in placental phenotype support fetal growth during undernutrition of pregnant mice. J Physiol. 2010;588(Pt 3):527-38.

121. Coan PM, Angiolini E, Sandovici I, Burton GJ, Constância M, Fowden AL. Adaptations in placental nutrient transfer capacity to meet fetal growth demands depend on placental size in mice. J Physiol. 2008;586(18):4567-76.

122. May PA, Tabachnick B, Hasken JM, Marais AS, de Vries MM, Barnard R, et al. Who is most affected by prenatal alcohol exposure: boys or girls? Drug Alcohol Depend. 2017;177:258-67.

123. Chen L, Nyomba BL. Effects of prenatal alcohol exposure on glucose tolerance in the rat offspring. Metabolism. 2003;52(4):454-62.

124. Harper KM, Tunc-Ozcan E, Graf EN, Redei EE. Intergenerational effects of prenatal ethanol on glucose tolerance and insulin response. Physiol Genom. 2014;46(5):159-68.

125. Segovia SA, Vickers MH, Gray C, Reynolds CM. Maternal obesity, inflammation, and developmental programming. Biomed Res Int 2014;2014:418975.

126. Kalisch-Smith JI, Simmons DG, Dickinson H, Moritz KM. Review: sexual dimorphism in the formation, function and adaptation of the placenta. Placenta. 2017;54:10-6.

127. O'Shea RS, Dasarathy S, McCullough AJ. Practice parameters committee of the American College of Gastroenterology. Alcoholic liver disease. Hepatology. 2010;51(1):307-28.
128. Habbick BF, Zaleski WA, Casey R, Murphy F. Liver abnormalities in three patients with fetal alcohol syndrome. Lancet. 1979;1(8116):580-1.

129. Møoller J, Brandt NJ, Tygstrup I. Hepatic dysfunction in patient with fetal alcohol syndrome. Lancet. 1979;1(8116):605-6.

130. Lefkowitch JH, Rushton AR, Feng-Chen KC. Hepatic fibrosis in fetal alcohol syndrome. Pathologic similarities to adult alcoholic liver disease. Gastroenterology. 1983;85(4):951-7.

131. Yang $X$, Schadt EE, Wang S, Wang H, Arnold AP, Ingram-Drake L, et al. Tissue-specific expression and regulation of sexually dimorphic genes in mice. Genome Res. 2006;16(8):995-1004.

132. Zietek T, Daniel H. Intestinal nutrient sensing and blood glucose control. Curr Opin Clin Nutr Metab Care. 2015;18(4):381-8.

133. Lee JT, Bartolomei MS. X-inactivation, imprinting, and long noncoding rnas in health and disease. Cell. 2013;152(6):1308-23.

134. Perera F, Herbstman J. Prenatal environmental exposures, epigenetics, and disease. Reprod Toxicol. 2011;31(3):363-73.

135. Hobbs CA, Chowdhury S, Cleves MA, Erickson S, MacLeod SL, Shaw GM, et al. Genetic epidemiology and nonsyndromic structural birth defects: from candidate genes to epigenetics. JAMA Pediatr. 2014;168(4):371-7.

136. Passaro KT, Little RE, Savitz DA, Noss J. Effect of paternal alcohol consumption before conception on infant birth weight. ALSPAC study team. Avon longitudinal study of pregnancy and childhood. Teratology. 1998;57(6):294-301.
Ready to submit your research? Choose BMC and benefit from:

- fast, convenient online submission

- thorough peer review by experienced researchers in your field

- rapid publication on acceptance

- support for research data, including large and complex data types

- gold Open Access which fosters wider collaboration and increased citations

- maximum visibility for your research: over $100 \mathrm{M}$ website views per year

At BMC, research is always in progress.

Learn more biomedcentral.com/submissions 